
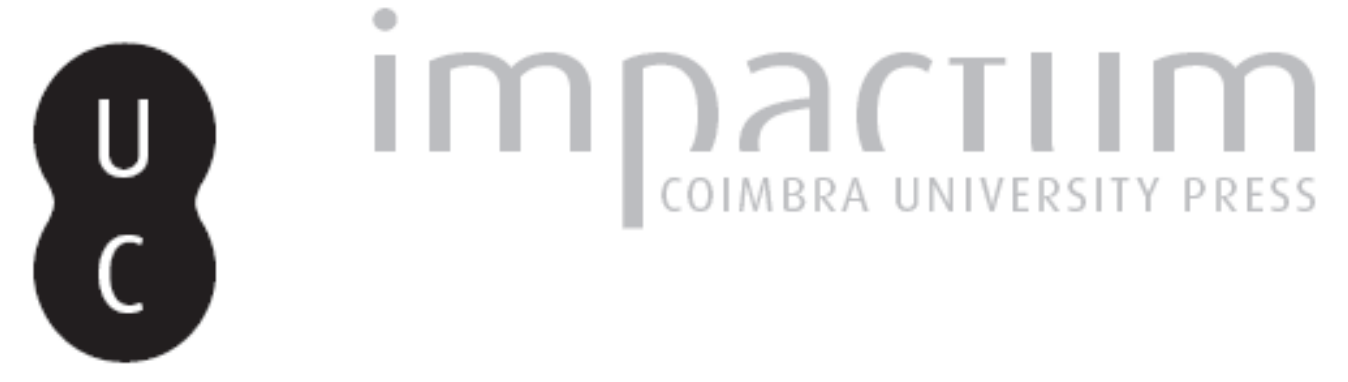

\title{
Espaços verdes no interior do tecido urbano de Coimbra, Portugal: contrastes topoçlimáticos, influência bioclimática e riscos de poluição atmosférica
}

\author{
Autor(es): $\quad$ Ganho, Nuno \\ Publicado por: Associação Portuguesa de Riscos, Prevenção e Segurança \\ URL \\ persistente: \\ URI:http://hdl.handle.net/10316.2/40164 \\ DOI: \\ DOI:https://doi.org/10.14195/1647-7723_3_5 \\ Accessed : $\quad$ 26-Apr-2023 15:27:12
}

A navegação consulta e descarregamento dos títulos inseridos nas Bibliotecas Digitais UC Digitalis, UC Pombalina e UC Impactum, pressupõem a aceitação plena e sem reservas dos Termos e Condições de Uso destas Bibliotecas Digitais, disponíveis em https://digitalis.uc.pt/pt-pt/termos.

Conforme exposto nos referidos Termos e Condições de Uso, o descarregamento de títulos de acesso restrito requer uma licença válida de autorização devendo o utilizador aceder ao(s) documento(s) a partir de um endereço de IP da instituição detentora da supramencionada licença.

Ao utilizador é apenas permitido o descarregamento para uso pessoal, pelo que o emprego do(s) título(s) descarregado(s) para outro fim, designadamente comercial, carece de autorização do respetivo autor ou editor da obra.

Na medida em que todas as obras da UC Digitalis se encontram protegidas pelo Código do Direito de Autor e Direitos Conexos e demais legislação aplicável, toda a cópia, parcial ou total, deste documento, nos casos em que é legalmente admitida, deverá conter ou fazer-se acompanhar por este aviso.

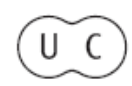




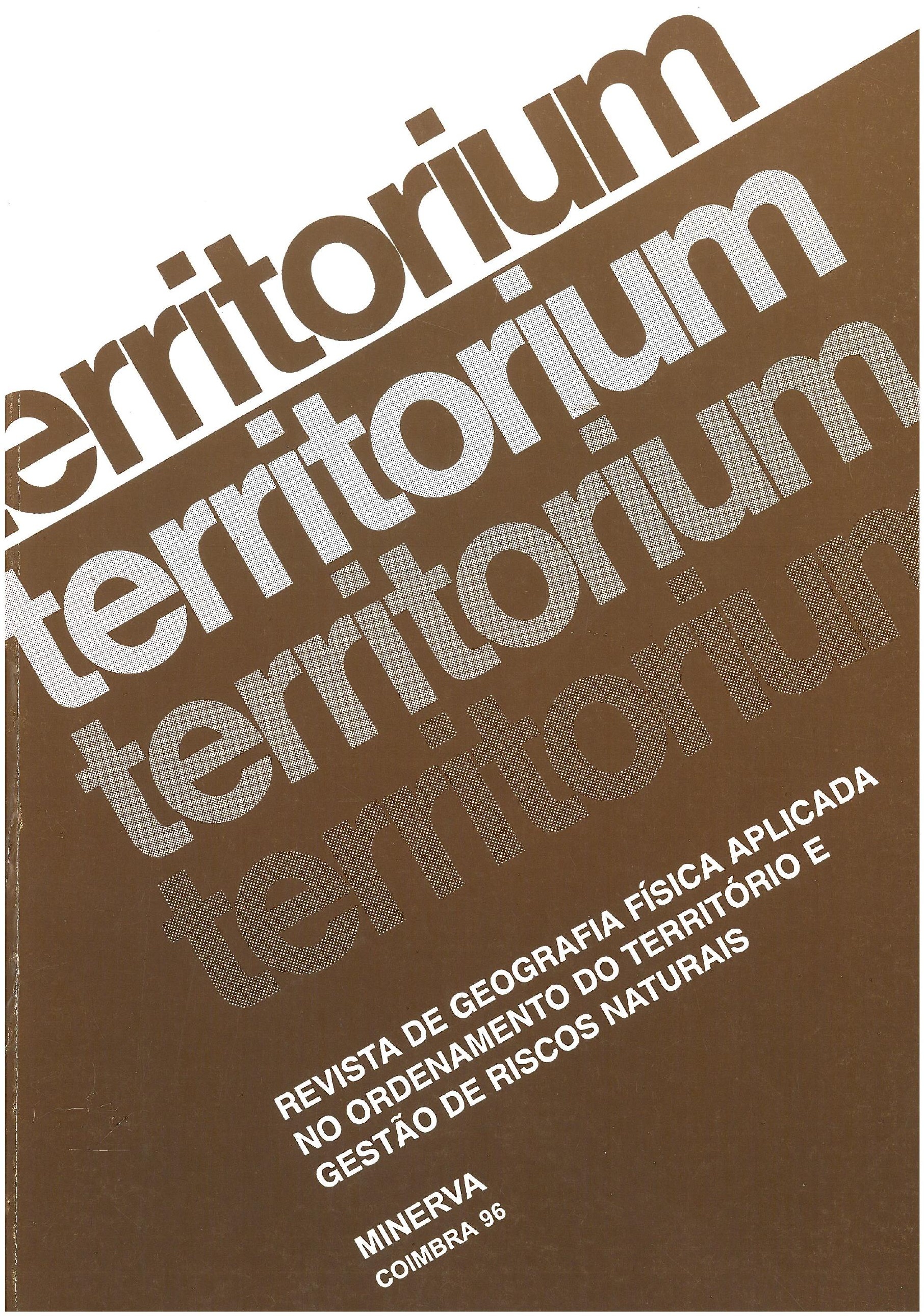




\title{
Espaços verdes no interior do tecido urbano de Coimbra, Portugal: Contrastes topoclimáticos, influência bioclimática e riscos de poluição atmosférica
}

\author{
Nuno Ganho*
}

\begin{abstract}
Resumo:
A partir de campanhas de observação itinerante de temperatura e de humidade relativa efectuadas no interior do tecido urbano de Coimbra (Portugal) e contemplando pontos de espaços verdes, analisam-se os contrastes topoclimáticos associados a estes espaços verdes, bem como a sua influência bioclimática e discutem-se os seus efeitos locais nos riscos de poluição atmosférica.

Palavras chave:

Espaços verdes, Topoclimatologia, Bioclimatologia, riscos naturais, poluição atmosférica, Coimbra.

Résumé:

À partir de mesures itinérantes de température et humidité relative efféctuées à l'intérieur du tissu urbain de Coimbra (Portugal), points d'espaces verts inclus, on analyse les contrastes topoclimatiques associés à ces espaces verts, ainsi que leur influence bioclimatique, et on discute leurs effects locaux sur les risques de pollution atmospherique.

Mots clés:

Espaces verts, Topoclimatologie, Bioclimatologie, risques naturels, pollution atmospherique, Coimbra.

Abstract:

Based on temperature and relative humidity measures made in the urban tissue of Coimbra (Portugal) and contempling points of green spaces, we analyse the topoclimatic contrasts made by those green spaces and their bioclimatic influence, and we discuss their local effects on the risks of atmospheric pollution.

Key words:

Green spaces, Topoclimatology, Bioclimatology, natural risks, atmospheric pollution, Coimbra.
\end{abstract}

\section{Introdução}

\subsection{O topoclima dos espaços verdes urbanos}

À escala de pormenor, aos espaços verdes correspondem características topoclimáticas próprias ${ }^{11} \mathrm{e}$ diferentes do espaço urbanizado no contex to do qual se encontram inseridos, tanto mais diferentes quanto mais denso é o povoamento, especialmente tratando-se de um povoamento arbóreo de espécies de médio e grande porte (fig. 1).

* Instituto de Estudos Geográficos, Faculdade de Letras, Universidade de Coimbra.

(1)A este propósito indicam-se as seguintes obras onde o assunto é tratado de forma mais ou menos aprofundada e que serviram de base para a elaboracão do ponto 1.1. do presente texto: GEIGER, 1961, pp. 307-379; OKE, 1987 pp. 141-157; BARRY e CHORLEY, 1985, pp. 370-385; ESCOURROU, 1981, pp. 120-123.
Relativamente ao espaço construído, os espaços verdes arbóreos apresentam, em geral, um albedo mais fraco, que aumenta à medida que o coberto vegetal se vai tornando mais aberto, absorvendo ao nível das copas, como consequência, a maior parte da radiação solar incidente, chegando muito pouca radiação ao espaço dos fustes e ao solo. Esta perda é maior em situações de fraca nebulosidade do que com condições de forte nebulosidade uma vez que a radiação difusa penetra mais facilmente pela folhagem do que a radiação directa. Consequentemente, abaixo do espaço das copas, verifica-se também uma redução da duração de iluminação: o dia começa mais tarde e termina mais cedo. Em função deste efeito de sombra, o balanço térmico diurno do solo, embora positivo, é atenuado relativamente ao balanço térmico das copas e dos espaços abertos ou urbanizados. 

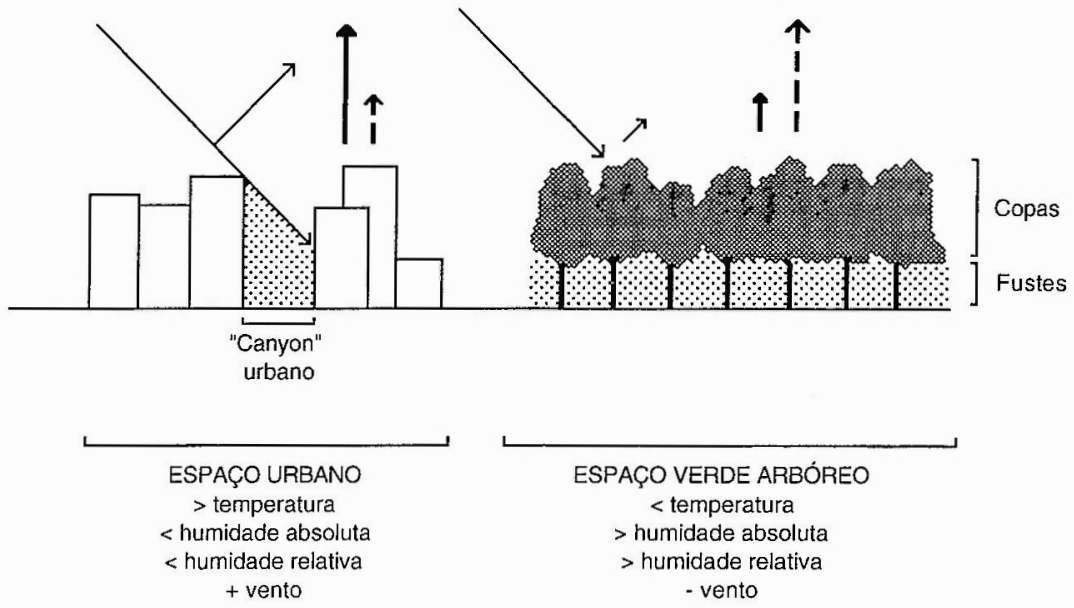

NOTA: os sinais $>,<,+\epsilon-$, indicam o sentido das variáveis climáticas do espaço urbano relativamente ao espaço verde arbóreo e vice-versa.

LEGENDA:

Fig. 1 - Esquema simplificado da influência topoclimática dos espaços verdes arbóreos

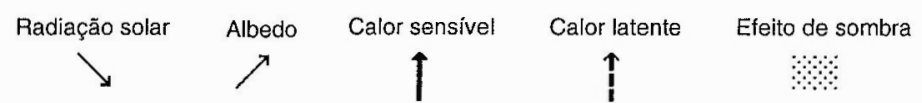

Uma parte da energia absorvida pelo povoamento arbóreo é consumida durante o dia pela fotossíntese e transformada em energia química, sendo libertada energia, pela fotólise, durante o dia e a noite, na mesma ordem de grandeza da consumida na fotossíntese. No entanto, as quantidades de energia envolvidas no metabolismo das plantas são quantitativamente tão insignificantes no contex to do balanço energético dos espaços arbóreos que podem ser desprezadas.

Atendendo à maior absorção de energia por parte dos espaços com ocupação arbórea, em relação aos espaços abertos ou urbanizados, seria de esperar que, pelo menos ao nível das copas, este facto se traduzisse por temperaturas mais elevadas. No entanto, tal não se verifica em consequência da sua maior disponibilidade em água, retida nos solos e transferida para o ar pela evapotranspiração, o que corresponde a um incremento do fluxo de calor latente em detrimento do fluxo de calor sensível, que se manifesta por um arrefecimento das folhas e do ar envolvente, especialmente sensivel na superfície activa da parte superior das copas. No espaço dos fustes, embora a evapotranspiração não seja tão significativa, a pouca radiação que atinge o solo atenua o aquecimento diurno. De noite, como consequência da contrairradiação das copas, o sinal negativo do balanço térmico do solo é atenuado, podendo manifestar-se por temperaturas do ar mais elevadas no espaço dos fustes do que nas copas ou na atmosfera dos espaços abertos. O certo é que, como consequência de um balanço térmico de características particulares, os espaços verdes arbóreos apresentam normalmente temperaturas mais baixas do que o espaço urbanizado em que se inserem, como revelam numerosos estudos de Climatologia Urbana em que, paralelamente a observações feitas em locais urbanizados, são também contemplados pontos de observação em espaços verdes integrados no tecido urbano. Estas diferenças térmicas são na ordem de $3^{\circ} \mathrm{C}$ em Washington D. C. (LANDSBERG, 1981, p. 232), de $2^{\circ} \mathrm{C}$ em Montréal (OKE, 1987, p. 301, fig. 8.20 ) ou de 3 a $4^{\circ} \mathrm{C}$ em Madrid (LÓPEZ GÓMEZ et all., 1993, p. 39; LÓPEZ GÓMEZet all., 1991,p. 19; COCA, 1992)e repercutem-se normalmente nas áreas envolventes, tudo dependendo da dimensão dos espaços verdes, do seu contexto topográfico e da morfologia urbana. $\mathrm{Na}$ Cidade do México, por exemplo, a influência térmica de um parque de 500ha (Chapultepec) faz-se sentir num raio de $2 \mathrm{~km}$, baixando a temperatura a $700 \mathrm{~m}$ do parque em $1^{\circ} \mathrm{C}$ na época húmida e $4^{\circ} \mathrm{C}$ no período seco (ESCOURROU, 1991, p. 63).

A maior disponibilidade em água e o incremento da evapotranspiração contribuem para um enriquecimento do ar em vapor de água, que se traduz por maiores valores de humidade absoluta nos espaços verdes arbóreos do que no espaço urbano en volvente. No entanto, tal acréscimo da humidade absoluta, por si só, traduzir-se-ia num aumento pouco significativo 
da humidade relativa. Os maiores valores de humidade relativa que realmente se verificam são determinados mais pela diminuição da capacidade higrométrica do ar em função da temperatura, do que do enriquecimento do ar em vapor de água.

A acção dos espaços verdes arbóreos manifesta-se ainda por uma diminuição da velocidade do vento, particularmente sensível no espaço dos fustes e tanto maior quanto mais perto do solo, bem como numa diminuição significativa do teor atmosférico em suspensões sólidas, funcionando como importantes filtros de poluição atmosférica.

Os contrastes climáticos que se estabelecem entre os espaços verdes e o espaço urbanizado em que estes se inserem, embora apresentando um carácter permanente, manifestam-se de maneira mais sensível sob condições de tempo seco, forte insolação e estabilidade atmosférica, durante as quais os efeitos de sombra e da evapotranspiração são maximizados e se traduzem por contrastes térmicos e consequentemente higrométricos.

\subsection{Os espacos verdes urbanos e seus efeitos bioclimáticos e nos riscos de poluição atmosférica}

As sensações de maior ou menor conforto ou desconforto do organismo humano dependem, entre muitos outros factores, da ambiência atmosférica, através de combinaçōes assumidas por variáveis climáticas como a radiação solar, a temperatura, o estado higrométrico do ar e o vento. Com o intuito de materializar, através da sua quantificação, tais sensações, existem diversos índices de conforto (MATHER, 1974, pp. 238-254; OLIVER, 1981, pp. 190-192) em que intervêm, directa ou indirectamente, estas variáveis climáticas. Ora, os espaços verdes urbanos, criando localmente um clima com uma identidade própria e diferente do clima do espaço urbanizado envolvente, criam também uma ambiência atmosférica, normalmente mais favorável do ponto de vista bioclimático, embora tais "juízos de valor" dependam das características do clima regional em que se inserem (GIVONI, 1991). Em cidades com climas quentes e secos, a diminuição da velocidade do vento e o aumento da humidade relativa que determinam, são compensados pela diminuição da radiação solar directa e da temperatura no aumento do grau de conforto bioclimático. Já nas áreas urbanas em regiões de clima quente e húmido, embora o efeito de sombra que criam seja positivo do ponto de vista bioclimático, este é contrariado pela diminuição da velocidade do vento e pelo aumento da humidade relativa, o que se pode traduzir por um aumento do grau de desconforto, sendo aconselhável nestes casos não enveredar por povoamentos arbóreos fechados. Sob condições de clima frio, a ocupação arbórea de espaços no interior de aglomerações urbanas contribui para uma diminuição local da velocidade do vento, o que é positivo do ponto de vista bioclimático, mas deverá ser feito de forma a não bloquear a radiação solar directa, para se obter efectivamente uma ambiência atmosférica com maior grau de conforto.

Estes raciocínios aplicam-se não só a espaços verdes, mais ou menos vastos, de uma aglomeração urbana, mas também à integração de vegetação arbórea no próprio tecido urbano (avenidas, praças e jardins de habitações individuais). Estudos experimentais sobre o efeito térmico de plantas em áreas urbanas (PARKER, 1983, 1987, 1989, citado por GIVONI, 1991) revelam, em tardes quentes e de forte insolação, uma redução nas temperaturas médias de paredes de $13.5-15.5^{\circ} \mathrm{C}$ por efeito de sombra de árvores. A $1 \mathrm{~m}$. do solo, no campus da UCLA (Universidade da California, Los Angeles), uma amostra de 70 dias de medição mostrou, com condiçães de céu limpo, especialmente no Verão, diferenças de temperatura até $3^{\circ} \mathrm{C}$ entre o ar acima de áreas pavimentadas expostas à radiação directa e áreas sob o efeito de sombra de árvores (AL HEMIDDI, citado por GIVONI, 1991).

Os resultados de um estudo feito em cidades dos E.U.A. (HUANG, 1987) permitem atribuir as causas fundamentais do arrefecimento determinado por plantas mais ao incremento da evapotranspiração do que ao efeito de sombra.

Independentemente das causas subjacentes a este arrefecimento, os efeitos traduzem-se - especialmente em cidades onde o calor é um dos principais factores de desconforto - numa melhoria da ambiência atmosférica dos espaços construídos, atenuando a intensidade da ilha de calor urbano e repercutem-se também no interior dos edifícios, atenuando os gastos energéticos e assim os custos inerentes à refrigeração do ambiente.

Do ponto de vista dos riscos de poluição atmosférica, os espaços verdes, ao diminuirem o teor do ar em suspensões sólidas e em dióxido de carbono, contribuem indubitavelmente para, localmente, atenuarem os níveis de poluição atmosférica. No entanto, como as situações de poluição atmosférica não surgem somente na dependência da densidade e intensidade das fontes poluidoras, mas também de condições atmosféricas de carácter regional e local inibidoras da dispersão dos poluentes, os espaços verdes, constituindo núcleos frios no campo térmico local, vão determinarcirculações específicas e uma estrutura térmica vertical da camada atmosférica directamente por eles influenciada que, em função do seu contexto topográfico podem, em espaços próximos, fomentar condições inibidoras da dispersão de poluentes. 


\subsection{Objectivos}

Pode então facilmente deduzir-se que, relativamente à influência topoclimática de espaços verdes urbanos e seus consequentes efeitos bioclimáticos e nos riscos de poluição atmosférica, encontrar leis gerais de carácter universal que, ao pormenor, possam ser padronizadas com o objectivo da sua aplicação ao ordenamento urbano de qualquer espaço, é uma tarefa não só difícil como desaconselhável. Cada caso deve ser objecto de um estudo prévio à implementação de um projecto de urbanização, de "per si", em função de condicionalismos geográficos de carácter regional - como o mesoclima - e de carácter local-características topoclimáticas, contexto topográfico, morfologia urbana, entre outros.

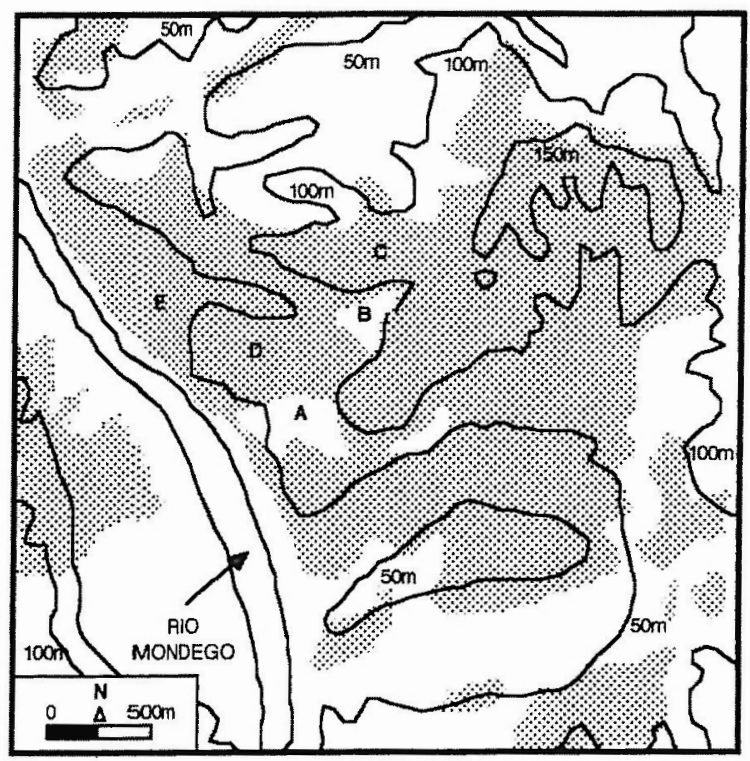

Linhas a cheio: curvas de nivel; Sombreado: espaço urbanizado A: Jardim Botânico; B: Parque de Santa Cruz;

C: Celas; D: "Alta"; E: "Baixa"

É consciente desta problemática que se apresenta este estudo, cujos objectivos fundamentais são o de diagnosticar a influência climática, à escala local, de dois espaços verdes da cidade de Coimbra - o Jardim Botânico e o Parque de Santa Cruz -, analizar o seus efeitos na ambiência atmosférica do ponto de vista do conforto bioclimático e discutir a sua acção na qualidade do ar das áreas envolventes, para que as conclusões inferidas possam ser convenientemente utilizadas noutros locais da aglomeração urbana que sejam, num futuro próximo, objecto de intervenção urbanística.

Tanto o Jardim Botânico como o Parque de Santa Cruz (fig. 2) constituem os dois principais espaços verdes da cidade de Coimbra, totalmente integrados no tecido urbano e vocacionados para o lazer. Embora de dimensões modestas - respectivarnente com 0.13 e $0.07 \mathrm{~km}^{2}$ de área aproximada - apresentam uma grande densidade vegetal e riqueza de espécies, com árvores de grande e de médio porte, entre folhosas e resinosas, e um substrato arbustivo denso e bem desenvolvido.

O Jardim Botânico ocupa um valeiro da margem esquerda do Mondego e que margina a Sul a colina onde se situa a "Alta" da cidade.

Fig. 2 - Localização do Jardim Botânico e do Parque de Santa Cruz no contexto da topografia e da mancha de povoamento urbano de Coimbra

O Parque de Santa Cruz ocupa parte da bacia de recepção de um vale encaixado que limita a Norte a mesma colina e cujo talvegue é percorrido por uma das principais artérias da cidade (Av. Sáda Bandeira), que desemboca na "Baixa".

Embora constituindo os espaços sobre os quais se objectiva este trabalho, a necessidade de os contextualizar, do ponto de vista climático, no espaço urbano em que se inserem, exigiu que a recolha de dados no terreno contemplasse uma área mais vasta e diversificada, quer do ponto de vista topográfico, quer quanto à morfologia urbana. 


\section{Metodologia}

\subsection{Obtenção dos dados ${ }^{(2)}$}

A obtenção dos dados topoclimáticos foi feita através de campanhas de observações itinerantes, em 18 pontos do espaço em análise, criteriosamente definidos em função de parâmetros como a topografia, o tipo de ocupação do solo e a morfologia urbana, distribuídos ao longo de um percurso que se efectuou a pé (fig. 3). O percurso iniciava-se na área de Celas, passando pelo Parque de Santa Cruz (3 pontos de observação), pelas Praças da República e João Paulo II, pelo Jardim Botânico ( 3 pontos de observação) e

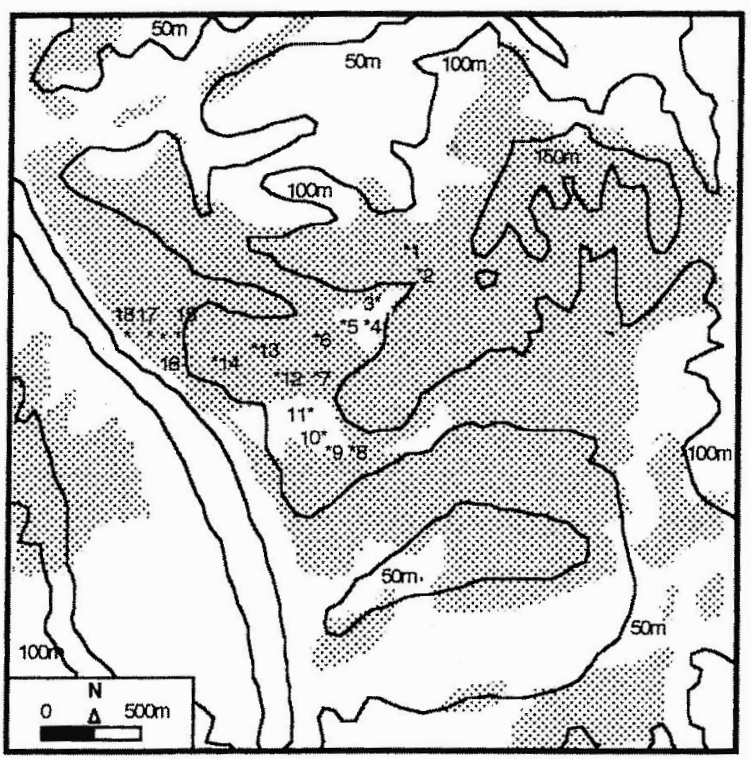

Locais de observação:

1- Av. Calouste Guibenkian; 2- R. Lourenço de Almeida Azevedo; 3, 4, 5 Parque de Santa Cruz; 6- Praça da república; 7-Praça Joāo Paulo II; 8Alameda Dr. Júlio Henriques; 9, 10,11-Jardim Botânico; 12- Praça D. Dinis; 13- R. Borges Carneiro; 14- Largo da Sé Velha; 15- R. Ferreira Borges; $16-$ Praça do Comércio; 17- R. Adelino Veiga; 18 - Av. Fernão de Magalhães

pela "Alta", terminando na "Baixa", contemplando assim, em diferentes posições topográficas, ruas com diferente orientação e volumetria, praças e espaços verdes. Os locais de observação e a sua caracterização sintética são apresentados no quadro 1.

As variáveis climáticas observadas foram a temperatura, a humidade relativa, a humidade absoluta e o ponto de saturação, embora não se tenham incluído

(2)Para a obterção dos dados contei com a imprescindível colaboração dos alunos da disciplina de Geografia do $3^{\circ}$ ano da Licenciatura em Arquitectura da Faculdade de Ciências e Tecnologia da Universidade de Coimbra, do ano lectivo de 1994/95, aos quais enderç̧o os meus agradecimentos. no presente trabalho as duas últimas. Utilizou-se um termohigrómetro digital devidamente aferido pelos instrumentos em abrigo do Instituto Geofísico da Universidade de Coimbra (IGU) que funcionou como estação de referência. O elemento sensível do termohigrómetro, na altura da medição, era sempre colocado à sombra, entre 1,5 a $2 \mathrm{~m}$ do solo e convenientemente afastado de muros ou paredes para atenuar, dentro do possível, os efeitos de factores microclimáticos.

As observações decorreram nos meses de Novembro e Dezembro de 1994, e de Janeiro, Junho e Julho de 1995, a diferentes horas do dia e sob diferentes condições de tempo (quadro 2).

Fig. 3 - Locais de cbservação: localizaçāo no contex to da topografia (linhas a cheio) e da mancha de povoamento urbanc (a sombreado). A linha do perfil quebrado define-se pela união, por segmentos de recta, dos pontos de observação (1 a 18), por ordem crescente.

$\mathrm{Na}$ totalidade efectuaram-se 26 campanhas de observação: 21 de Inverno e 5 de Verão, das quais 7 correspondentes ao período da manhã e 19 à tarde. Em 2 dos dias efectuaram-se 2 observações, uma de manhã e outra de tarde, e noutros 2 dias foi possível efectuar 5 observações, 2 de manhã e 3 de tarde, iniciando-se cada percurso menos de uma hora depois de findo o percurso anterior, tentando-se com este procedimento evidenciar o comportamento intradiurno do campo termohigrométrico local ${ }^{(3)}$.

(3) Não se efectuaram nunca observações nocturnas, apesar de se revestirem de grande interesse para um me'hor entendimento da realidade topoclimática, por um lado porque o Jardim Botânico se encontra encerrado durante a noite e por outro pelo perigo que constitui circular, à noite, no interior do Parque de Santa Cruz. 
Quadro 1

Locais de observação: designação e características

\begin{tabular}{|c|c|c|}
\hline $\begin{array}{l}\text { Numeração } \\
\text { do local de observação }\end{array}$ & \begin{tabular}{|l|} 
Designação \\
do local de observação
\end{tabular} & \begin{tabular}{|l|} 
Características \\
do local de observacão
\end{tabular} \\
\hline Pl & $\begin{array}{l}\text { Av. Calouste Gulbenkian } \\
\text { (frente ao Centro Cornercial } \\
\text { Primavera) }\end{array}$ & $\begin{array}{l}\text { Avenida larga, com } 4 \text { faixas de rodagem e } 2 \text { faixas laterais de } \\
\text { estacionamento e circulação pedonal, com orientação NE-SW, } \\
\text { ladeada por edifícios de } 8 \text { pisos, justapostos no seu lado } \\
\text { meridional. Tr̂ansito automóvel significativo. }\end{array}$ \\
\hline P2 & $\begin{array}{l}\text { R. Lourenço de Almeida } \\
\text { Azevedo } \\
\text { (frente à entrada superior } \\
\text { lateral do Jardim de Santa } \\
\text { Cruz) }\end{array}$ & $\begin{array}{l}\text { Rua com } 2 \text { faixas de rodagem, estacionamentos laterais e } \\
\text { passeios de circulação pedonal, arborizada, com orientação ENE- } \\
\text {-WSW, ladeada a W por edifícios de } 3 \text { a } 4 \text { pisos e a E pelo Jardim } \\
\text { de Santa Cruz. Tr̂ansito automóvel significativo. }\end{array}$ \\
\hline P3 & $\begin{array}{l}\text { Parque de Santa Cruz } \\
\text { (alameda das árvores) }\end{array}$ & $\begin{array}{l}\text { Alameda totalmente recoberta por árvores de médio e grande } \\
\text { porte, no interior do parque. }\end{array}$ \\
\hline P4 & $\begin{array}{l}\text { Parque de Santa Cruz } \\
\text { (lago) }\end{array}$ & $\begin{array}{l}\text { Clareira com um diâmetro aproximado de } 20 \text { metros, ladeada por } \\
\text { árvores de médio e grande porte, ocupada por um lago de diâmetro } \\
\text { aproximado de } 15 \text { metros. }\end{array}$ \\
\hline P5 & $\begin{array}{l}\text { Parque de Santa Cruz } \\
\text { (fonte) }\end{array}$ & $\begin{array}{l}\text { Local situado no extremo de uma alameda totalmente recoberta } \\
\text { por árvores de médio e grande porte. }\end{array}$ \\
\hline P6 & Praça da República & $\begin{array}{l}\text { Praça de diâmetro aproximado de } 100 \text { metros, arborizada no seu } \\
\text { perímetro interno e ladeada por edifícios justapostos de } 4 \text { pisos. }\end{array}$ \\
\hline P7 & Praça João Paulo II & $\begin{array}{l}\text { Praça de diâmetro aproximado de } 50 \text { metros, pontualmente } \\
\text { ladeada por edifícios de } 2 \text { pisos. }\end{array}$ \\
\hline P8 & $\begin{array}{l}\text { Alameda Dr. Júlio Henri- } \\
\text { ques } \\
\text { (meio caminho entre os } \\
\text { Arcos do Jardim e o Jardim } \\
\text { Escola João de Deus) }\end{array}$ & $\begin{array}{l}\text { Av. com } 4 \text { faixas de rodagem e passeios de circulação pedonal, } \\
\text { parcialmente recoberta por árvores de médio porte, com orien- } \\
\text { tação SSE-NNW, ladeada a E por um pequeno jardim e a W pelo } \\
\text { Jardim Botânico. Tĥansito automóvel significativo. }\end{array}$ \\
\hline P9 & $\begin{array}{l}\text { Jardim Botânico } \\
\text { (alameda das árvores) }\end{array}$ & $\begin{array}{l}\text { Alameda totalmente recoberta por árvores de médio porte, no } \\
\text { interior do jardim. }\end{array}$ \\
\hline PIO & $\begin{array}{l}\text { Jardim Botânico } \\
\text { (lago) }\end{array}$ & $\begin{array}{l}\text { Clareira com um diâmetro aproximado de } 40 \text { metros, ladeada por } \\
\text { árvores de médio e grande porte, ocupada por árvores de pequeno } \\
\text { porte e arbustos dispersos, e um lago de diâmetro aproximado de } \\
10 \text { metros. }\end{array}$ \\
\hline P11 & $\begin{array}{l}\text { Jardim Botânico } \\
\text { (estufas) }\end{array}$ & Local totalmente recoherto por árvores de grande porte. \\
\hline $\mathrm{P} 12$ & Praça D. Dinis & $\begin{array}{l}\text { Praça de diâmetro aproximado de } 40 \text { metros, ladeada a } S \text { por um } \\
\text { edifício de } 5 \text { pisos (Faculdade de Matemática). }\end{array}$ \\
\hline P13 & $\begin{array}{l}\text { R. Borges Carneiro } \\
\text { (traseiras do Museu Macha- } \\
\text { do de Castro) }\end{array}$ & $\begin{array}{l}\text { Rua estreita e declivosa, com } 1 \text { faixa de rodagem, ladeada por } \\
\text { edifícios justapostos de } 5 \text { pisos. }\end{array}$ \\
\hline P14 & Largo da Sé Velha & $\begin{array}{l}\text { Praça de diâmetro aproximado de } 20 \text { metros, ladeada por edifícios } \\
\text { justapostos de } 4 \text { pisos e na sua parte E pelo compacto bloco } \\
\text { calcário da Sé Velha. }\end{array}$ \\
\hline P15 & $\begin{array}{l}\text { R. Ferreira Borges } \\
\text { (meio caminho entre o Arco } \\
\text { D'Almedina e as escadas de } \\
\text { São Tiago) }\end{array}$ & $\begin{array}{l}\text { Rua estreita, de largura equivalente a } 2 \text { faixas de rodagem, com } \\
\text { circulação exclusivamente pedonal, ladeada por edifícios } \\
\text { justapostos de } 5 \text { pisos, com orientação NNW-SSE. }\end{array}$ \\
\hline P16 & Praça do Comércio & $\begin{array}{l}\text { Praça rectangular, com dimensão aproximada de } 40 \times 200 \text { metros, } \\
\text { ladeada por edifícios justapostos de } 5 \text { a } 6 \text { pisos. }\end{array}$ \\
\hline $\mathrm{P} 17$ & $\begin{array}{l}\text { R. Adelino Veiga } \\
\text { (largo do Paço do Conde) }\end{array}$ & $\begin{array}{l}\text { Rua estreita, de largura equivalente a } 1 \text { faixa de rodagem, com } \\
\text { circulação exclusivamente pedonal, ladeada, por edifícios } \\
\text { justapostos de } 4 \text { pisos, com orientação WSW-Eive. }\end{array}$ \\
\hline P18 & $\begin{array}{l}\text { Av. Fernão de Magalhães } \\
\text { (à saída da R. Adelino } \\
\text { Veiga) }\end{array}$ & $\begin{array}{l}\text { Av. com } 3 \text { ou } 4 \text { faixas de rodagem e passeios laterais de circulação } \\
\text { pedonal, ladeada por edifícios de altura variável (de } 2 \text { a } 8 \text { pisos), } \\
\text { por vezes justapostos, com orientação NW-SE. Intenso trânsito } \\
\text { automóvel. }\end{array}$ \\
\hline
\end{tabular}


Quadro 2

Campanhas de observação itinerante efectuadas e condições de tempo vigentes

\begin{tabular}{|c|c|c|}
\hline Data $^{1}$ & Hora local ${ }^{2}$ & Condições de tempo ${ }^{3}$ \\
\hline $22.11 .94(\mathrm{I})$ & $15.05-16.05(\mathrm{~T})$ & Céu pouco nublado, vento fraco $(8 \mathrm{a} 4 \mathrm{~km} / \mathrm{h})$ de SE \\
\hline $29.11 .94(1)$ & $14.30-1.5 .51(\mathrm{~T})$ & Céu pouco nublado, vento moderado $(28$ a $18 \mathrm{~km} / \mathrm{h}$ ) de ESE a SE \\
\hline $6.12 .94(1)$ & $16.25-18.10(\mathrm{~T})$ & Céu muito nublado, vento fraco a moderado ( 22 a $13 \mathrm{~km} / \mathrm{h}$ ) de SSE \\
\hline $7.12 .94(\mathrm{I})$ & $14.35-15.27(\mathrm{~T})$ & Céu muito nublado, aguaceiros, vento fraco $(9$ a $12 \mathrm{~km} / \mathrm{h})$ de W \\
\hline \multirow[t]{2}{*}{8.12 .94 (I) } & $10.01-11.15(\mathrm{M})$ & Céu muito nublado, vento fraco $(16$ a $11 \mathrm{~km} / \mathrm{h})$ de SE \\
\hline & $15.26-16.35(\mathrm{~T})$ & Céu muito nublado, vento fraco $(15$ a $12 \mathrm{~km} / \mathrm{h})$ de $\mathrm{S}$ a SE \\
\hline \multirow[t]{2}{*}{$12.12 .94(\mathrm{I})$} & $10.45-11.40(\mathrm{M})$ & Céu limpo, vento fraco $(14$ a $11 \mathrm{~km} / \mathrm{h})$ de SE \\
\hline & $14.30-15.37(\mathrm{~T})$ & Céu pouco nublado, vento fraco $(7 \mathrm{a} 12 \mathrm{~km} / \mathrm{h})$ de SE \\
\hline \multirow[t]{5}{*}{$14.12 .94(I)$} & $10.00-11.06(\mathrm{M})$ & Céu limpo, vento fraco $(8$ a $9 \mathrm{~km} / \mathrm{h})$ de $S S E$ \\
\hline & $11.41-12.20(\mathrm{M})$ & Céu limpo, vento fraco $(9$ a $6 \mathrm{~km} / \mathrm{h})$ de SSE \\
\hline & $13.43-14.47(\mathrm{~T})$ & Céu limpo, vento fraco ( 6 a $3 \mathrm{~km} / \mathrm{h}$ ) de SSE rodando para WNW \\
\hline & $15.42-16.34(T)$ & Céu limpo, vento fraco (4 a $6 \mathrm{~km} / \mathrm{h})$ de WNW \\
\hline & $17.10-18.08(\mathrm{~T})$ & Céu muito nublado, vento fraco $(6$ a $1 \mathrm{~km} / \mathrm{h})$ de WSW \\
\hline $3.1 .95(\mathrm{I})$ & $14.55-15.47(\mathrm{~T})$ & Céu nublado, vento fraco $(5$ a $3 \mathrm{~km} / \mathrm{h}$ ) de $S W$ rodando para $N W$ e $N$ \\
\hline $4.1 .95(\mathrm{I})$ & $11.27-12.25(\mathrm{M})$ & Céu nublado, vento fraco (! a $4 \mathrm{~km} / \mathrm{h}$ ) de $\mathrm{N}$ a WNW \\
\hline $10.1 .95(\mathrm{I})$ & $14.58-16.25(\mathrm{~T})$ & Céu limpo, vento fraco ( 8 a $6 \mathrm{~km} / \mathrm{h}$ ) de $\mathrm{E}$ a NNE \\
\hline \multirow[t]{5}{*}{$11.1 .95(\mathrm{l})$} & $9.40-10.28(\mathrm{M})$ & Céu limpo, vento fraco $(5$ a $8 \mathrm{~km} / \mathrm{h})$ de $S E$ a $S$ \\
\hline & $11.39-12.34(\mathrm{M})$ & Céu limpo, vento fraco $(6$ a $3 \mathrm{~km} / \mathrm{h})$ de $S$ a $W$ \\
\hline & $13.43-14.40(\mathrm{~T})$ & Céu limpo, vento fraco $(3$ a $6 \mathrm{~km} / \mathrm{h})$ de W a NW \\
\hline & $15.52-17.04(\mathrm{~T})$ & Céu limpo, vento fraco $(6$ a $10 \mathrm{~km} / \mathrm{h})$ de NW a NNW \\
\hline & $17.47-19.13(\mathrm{~T})$ & Céu limpo, vento fraco $(6$ a $1 \mathrm{~km} / \mathrm{h})$ de NNW a W \\
\hline $8.6 .95(V)$ & $15.25-17.20(\mathrm{~T})$ & Céu limpo, vento fraco $(8$ a $15 \mathrm{~km} / \mathrm{h})$ de WNW \\
\hline $11.6 .95(\mathrm{~V})$ & $15.00-16.08(\mathrm{~T})$ & Céu pouco nublado, vento fraco $(10 \mathrm{a} 14 \mathrm{~km} / \mathrm{h})$ de $\mathrm{W}$ \\
\hline $15.6 .95(V)$ & $15.13-17.08(\mathrm{~T})$ & Céu pouco nublado, vento fraco $(7$ a $11 \mathrm{~km} / \mathrm{h})$ de $\mathrm{SW}$ \\
\hline $3.7 .95(\mathrm{~V})$ & $15.00-16.06(\mathrm{~T})$ & Céu encoberto, vento fraco $(9$ a $15 \mathrm{~km} / \mathrm{h})$ de $\mathrm{W}$ a NW \\
\hline $19.7 .95(\mathrm{~V})$ & $15.00-16.03(\mathrm{~T})$ & Céu limpo, vento fraco $(6$ a $11 \mathrm{~km} / \mathrm{h})$ de $\mathrm{W}$ \\
\hline
\end{tabular}

1 As letras (I) ou (V) apresentadas entre parentesis designam o periodo do ano a que se refere a campanha de observação, respectivamente Inverno ou Verão

2 As letras (M) ou (T) apresentadas entre parentesis designam o periodo do dia a que se refere a campanha de observação, respectivamente Manhã ou Tarde

3 As condiçōes de velocidade e direç̧ão do vento foram as que se observaran no Instituto Geofísico da Universidade no decurso da campanha de observação

Privilegiaram-se condições de tempo de pouca nebulosidade e vento fraco, por serem aquelas em que os contrastes topoclimáticos são, normalmente, maximizados, tendo apenas 6 campanhas de medição decorrido sob condições de forte nebulosidade, o que permite, eventualmente, tirar algumas conclusões àcerca da influência deste parâmetro no comportamento espacial das variáveis climáticas.

\subsection{Tratamento e apresentação dos dados}

Oprocedimento adoptado no tratamento dos dados obtidos através de observações no terreno foi idêntico ao que se seguiu em anteriores trabalhos (GANHO, 1992a, 1992b, 1995a, 1995b). Ao longo dos percursos, em cada local de medição, anotavam-se os valores das variáveis climáticas e a hora a que foram observados. 
Para eliminar, ou minorar, o efeito da sua variação no tempo durante o qual decorreu o percurso de medição, procedeu-se ao cálculo das diferenças entre os valores de temperatura e humidade relativa medidos, e os valores de temperatura e humidade relativa observados, emigual momento, no IGU e evidenciados pela curva do termohigrógrafo em abrigo. Obtêm-se assim valores relativos ao IGU de temperatura (Tr) e humidade relativa ( $\mathrm{HRr}$ ).

As séries de Tre de HRr de cada local de observação foram subdivididas em 3 conjuntos: observações em manhãs de Inverno, em tardes de Inverno e em tardes de Verão. Para cada uma destas subséries determinou-se a média, a mediana, o desvio-padrão e os extremos observados (máximo e mínimo) com vista à sua caracteri zação estatística ${ }^{(4)}$.

Tanto os valores medianos das variáveis como os valores observados em cada percurso de medição, são apresentados sob a forma de perfis térmicos e higrométricos correspondentes a um perfíl topográfico transversal quebrado, traçado ao longo de uma linha resultante da união, através de segmentos de recta, dos diferentes pontos de observação, por ordem crescente. Deste modo, evidenciam-se mais facilmente as relações entre a topografia, o tipo de ocupação do solo, a morfologia urbana e o comportamento espacial das variáveis climáticas.

Com o intuito de mais objectivamente caracterizar os contrastes espaciais das variáveis climáticas, assim como os contrastes termohigrométricos entre os espaços verdes e o espaço urbano envolvente, para cada uma das campanhas de observação efectuadas, procedeuse do seguinte modo:

- determinaram-se as diferenças de temperatura entre o local mais quente e o local mais fresco de todo o percurso de observação e as diferenças de humidade relativa entre o local mais húmido e o local mais seco do conjunto de pontos contemplados ao longo do percurso de observação, evidenciando-se deste modo os contrastes termohigrométricos espaciais totais;

- determinaram-se as diferenças de temperatura e de humidade relativa entre o local mais fresco, ou o local mais húmido, de cada um dos espaços verdes em análise e os locais, exteriores ao espaço verde, mais próximos. No caso do Parque de Santa Cruz o cálculo destas diferenças fez-se relativamente aos pontos P2 (Rua Lourenço de Almeida Azevedo) e P6 (Praça da República), e no caso do Jardim Botânico relativamente aos pontos P8 (Alameda Dr. Júlio Henriques) e P12 (Praça D. Dinis), calculando-se

\footnotetext{
(4)Optou-se por nĩo explorar a totalidade desta informação, no texto, que o tornaria exaustivo, sem que com este procedimento se negligenciassem os objectivos fundamentais da análise dos dados. A caracterização estatística das séries aparece assim condensada nos quadros 9,10 e 11 , apresentados em Anexo, permitindo ao leitor a sua consulta quando interessado em aspectos de pormenor:
}

depois a média das duas diferenças de temperatura e de humidade relativa obtidas para cada espaço verde, que, embora com um certo grau de abstracção, traduz a intensidade dos contrastes térmicos e higrométricos associados especificamente a estes espaços verdes; considerou-se também a maior das diferenças de temperatura e de humidade relativa obtidas entre cada um destes espaços verdes e os locais mais próximos, independentemente de ser relativamente a P2 ou P6 no caso de Parque de Santa Cruz, ou a P8 ou P12 no caso do Jardim Botânico, evidenciando-se assim a intensidade máxima dos contrastes térmicos e higrométricos determinados por estes espaços verdes;

- anotaram-se os pontos mais quentes e mais frescos, ou os pontos mais húmidos e mais secos de cada um dos espaços verdes.

Para as diferenças de temperatura e de humidade relativa calculou-se a mediana das séries formadas pelos valores correspondentes a manhãs de Inverno, a tardes de Inverno e a tardes de Verão.

No caso das séries formadas pelos locais mais quentes e mais frescos, ou mais húmidos e mais secos, determinaram-se as frequências relativas de ocorrência, para cada uma das mesmas séries consideradas.

Toda esta informação é apresentada em quadros que especificam e concretizam as informações veiculadas pelos perfis termohigrométricos.

Com base nos valores de temperatura e humidade relativa obtidos em cada campanha de observação, calculou-se também, para o IGU e para cada local de medição, o índice de desconforto ou índice de temperatura-humidade $(\mathrm{ITH})^{(5)}$, desenvolvido com o intuito de, de uma forma simples, avaliaro grau de desconforto associado a diferentes combinações destas variáveis climáticas (GILES et, all., 1990). Este índice obtém-se através da seguinte fórmula

$$
\mathrm{ITH}=\mathrm{T}-0.55(1-0.01 \mathrm{HR})(\mathrm{T}-14.5)
$$

onde $\mathrm{T}$ é a temperatura do ar $\mathrm{em}{ }^{\circ} \mathrm{C}$ e $\mathrm{HR}$ a humidade relativa.

De acordo com observações experimentais, para um ITH inferior a 21 não são observadas sensações de desconforto. À medida que o índice cresce acima deste limiar, uma proporção crescente de indivíduos manifesta sensações de desconforto. Assim, para um ITH com valores entre 21 e 23.9, até 50\% da população estudada manifesta sensaçôes de desconforto; para valores de 24 a 26.9 , mais de $50 \%$ da população sente desconforto, entre 27 e 28.9 a maior parte dos indivíduos acusam desconforto e entre $29 \mathrm{e} 31.9$ todos os indivíduos

(5) Não se contemplaram neste trabalho outros índices bioclimáticos, alguns dos quais mais completos porque fazendo intervir também outras variáveis de primordial importância na avaliação da ambiência atmosférica (MATHER, 1974), como é o caso do vento, por nāo se dispor de valores destas variáveis. 
sentem forte stress bioclimático. Valores de ITH superiores a 32 correspondem a um "estado de emergência médica".

Para os dias de medição em que se obtiveram, em alguns ou em todos os locais, valores de ITH superiores a 21 (o que só aconteceu em tardes de Verão), apresentam-se também estes dados sob a forma de perfis de desconforto, que se relacionam com os correspondentes perfis termohigrométricos e topográfico.

\section{Resultados}

\subsection{Influência topoclimática do Parque de Santa Cruz e do Jardim Botânico}

\section{Os valores medianos}

Os perfis da figura 4 revelam contrastes significativos de temperatura e de humidade relativa ao longo do percurso de observação, tanto em manhãs de Inverno, como nas tardes de Inverno ou de Verão, em associação evidente com diferentes tipos de ocupação do solo e com a morfologia urbana. Uma parte importante destes contrastes termohigrométricos espaciais são determinados pelos espaços verdes, aos quais correspondem os maiores e menores valores medianos, respectivamente, de humidade relativa e temperatura, relativas ao IGU. Estes espaços verdes constituem, assim, células de frescura e de humidade no interior do campo termohigrométrico urbano. No conjunto de 26 percursos de observação efectuados, apenas em 3 ( $11.5 \%$ da amostra) - 1 numa manhã de Inverno, 1 numa tarde de Inverno e 1 numa tarde de Verão - as temperaturas do Parque de Santa Cruz eram superiores às do espaço urbano envolvente e, no caso do Jardim Botânico, este facto verificou-se em apenas 2 percursos ( $7.7 \%$ da amostra), respectivamente numa manhã e numa tarde de Inverno. Em nenhum dos percursos efectuados os valores de humidade relativa observados nestes espaços verdes foram inferiores aos do espaço urbano envolvente.

De acordo com os dados apresentados no quadro 3 , os valores medianos dos contrastes térmicos observados para o conjunto total de pontos de observação são iguais em tardes de Inverno e de Verão $\left(2.9^{\circ} \mathrm{C}\right)$ e ligeiramente superiores aos valores de manhãs de Inverno $\left(2.7^{\circ} \mathrm{C}\right)$.

O efeito térmico dos espaços verdes considerados, relativamente ao espaço urbano envolvente, não difere
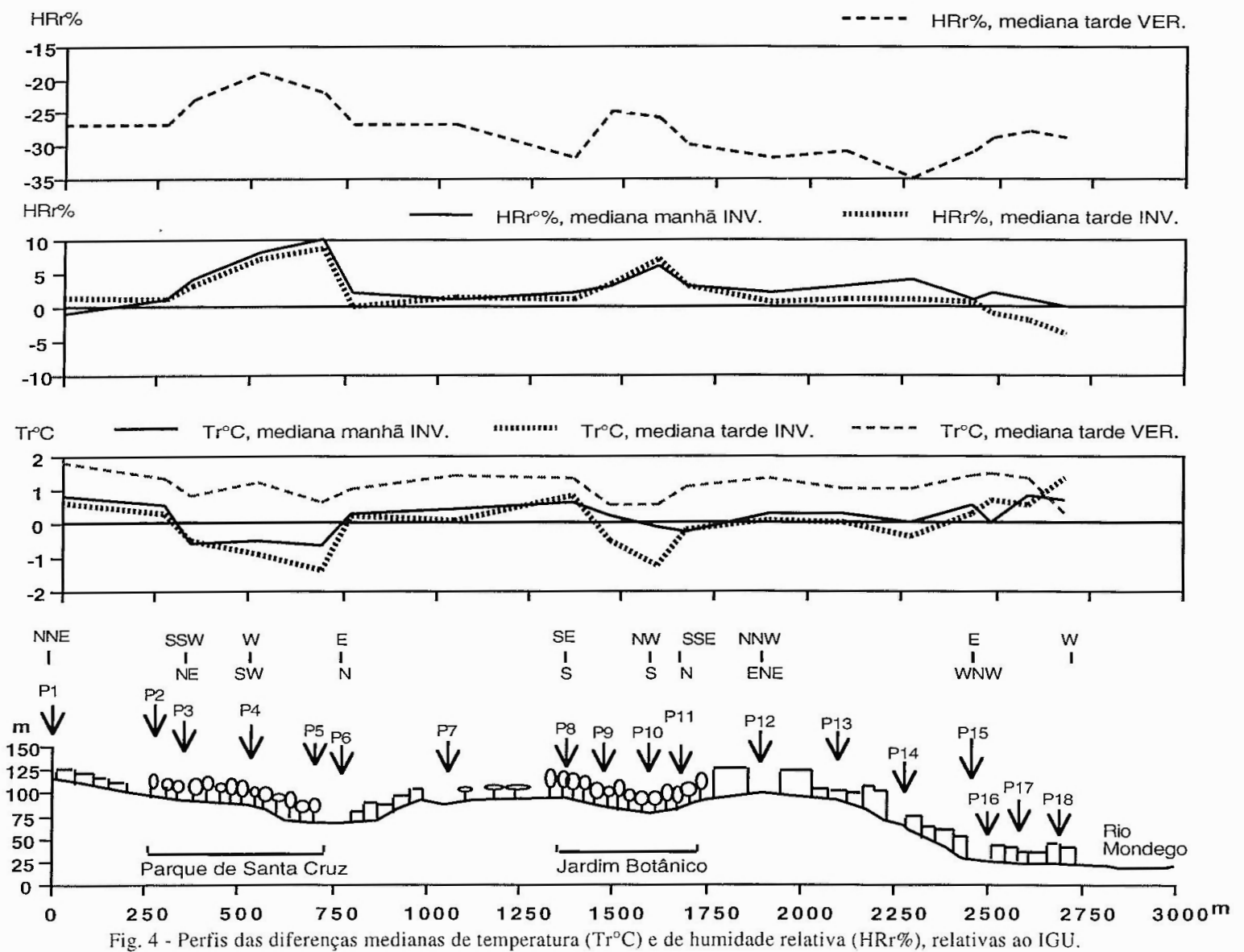
Quadro 3

Contrastes térmicos medianos para as subséries de percursos de observação

\begin{tabular}{|c|c|c|c|c|c|c|c|}
\hline & $\begin{array}{l}\text { mediana } \\
\mathrm{T}>-\mathrm{T}<\end{array}$ & $\begin{array}{c}\text { mediana } \\
{[(\text { TSC-T2)+(TSC-T6) }] / 2} \\
\end{array}$ & $\begin{array}{r}\text { mediana } \\
\text { TSCmáx. }\end{array}$ & PSC T< & $\begin{array}{c}\text { mediana } \\
{[(\mathrm{TB}-\mathrm{T} 8)+(\mathrm{TB} \cdot \mathrm{T} 12)] / 2} \\
\end{array}$ & $\begin{array}{l}\text { mediana } \\
\text { TBmáx. }\end{array}$ & $\mathrm{PB} \mathrm{T}<$ \\
\hline $\begin{array}{l}\text { Manhãs } \\
\text { Inverno }\end{array}$ & 2.7 & -0.9 & -1.2 & $\begin{array}{l}\text { P5 (57.1) } \\
\text { P4 (42.9) }\end{array}$ & -1.5 & -1.5 & $\mathrm{P} 10(100)$ \\
\hline $\begin{array}{l}\text { Tardes } \\
\text { Inverno }\end{array}$ & 2.9 & -1.3 & -1.7 & $\begin{array}{c}\text { P5 }(78.6) \\
\text { P4 (14.3) } \\
\text { P3 (7.1) }\end{array}$ & -1.4 & -1.7 & $\begin{array}{l}\mathrm{P} 10(78.6) \\
\mathrm{P} 9(14.3) \\
\operatorname{P} 11(7.1)\end{array}$ \\
\hline $\begin{array}{l}\text { Tardes } \\
\text { Verão }\end{array}$ & 2.9 & -0.6 & -0.7 & $\begin{array}{l}\text { P3 }(60.0) \\
\text { P5 }(30.0) \\
\text { P4 }(10.0) \\
\end{array}$ & -0.7 & -1.2 & $\begin{array}{c}\text { P9, P10 } \\
(40.0) \\
\text { P11 }(20.0)\end{array}$ \\
\hline
\end{tabular}

Mediana $\mathrm{T}>-\mathrm{T}<$ : mediana das diferenças de temperatura entre o local mais quente e o local mais fresco de todo o percurso de observação

Mediana [(TSC-T2)+(TSC-T6)]/2: mediana das médias das diferenças de temperatura entre o local mais fresco do Parque de Santa Cruz (TSC) e a Rua Lourenço de Almeida Azevedo (T2), bem como a Praça da República (T6)

Mediana TSCmáx.: mediana das máximas diferenças de temperatura entre o local mais fresco do Parque de Santa Cruz (TSC) e a Rua Lourenço de Almeida Azevedo (T2), bem como a Praça da República (T6)

PSC T<: locais do Parque de Santa Cruz com a temperatura mais baixa, por ordem decrescente de frequência de ocorrência, cujo vaior relativo à amostra considerada, em percentagem, é apresentado entre parentesis

Mediana [(TB-T8)+(TB-T12)]/2: mediana das médias das diferenças de temperatura entre o local mais fresco do Jardim Botânico (TB) e a Alameda Dr. Júlio Henriques (T8), bem como a Praça D. Dinis (T12)

Mediana TBmáx.: mediana das máximas diferenças de temperatura entre o local mais fresco do Jardim Botânico (TB) e a Alameda Di. Júlio Henriques (T8), bem como a Praça D. Dinis (T12)

PB T<: locais do Jardim Botânico com a temperatura mais baixa, por ordem decrescente de frequência de ocorrência, cujo valor relativo à amostra considerada, em percentagem, é apresentado entre parentesis

Quadro 4

Contrastes higrométricos medianos para as subséries de percursos de observação

\begin{tabular}{|c|c|c|c|c|c|c|c|}
\hline & $\begin{array}{l}\text { mediana } \\
\mathrm{HR}>-\mathrm{HR}<\end{array}$ & $\begin{array}{l}\text { mediana } \\
{[(\text { HRSC-HR2)+(HRSC- }} \\
\text { HR6)]/2 }\end{array}$ & $\begin{array}{l}\text { mediana } \\
\text { HRSCmáx. }\end{array}$ & PSC HR> & $\begin{array}{c}\text { mediana } \\
{[(\text { HRB-HR } 8)+(\text { HRB }-H R 12)] / 2} \\
\end{array}$ & $\begin{array}{l}\text { mediana } \\
\text { HRBmáx. }\end{array}$ & PB HR> \\
\hline $\begin{array}{l}\text { Manhãs } \\
\text { Inverno }\end{array}$ & 13.0 & 10.0 & 11.0 & $\begin{array}{l}\text { P.5 (71.4) } \\
\text { P3, P4 } \\
(14.3)\end{array}$ & 4.0 & 5.0 & $\begin{array}{l}\text { PI0 (71.4) } \\
\text { PII (28.6) }\end{array}$ \\
\hline $\begin{array}{c}\text { Tardes } \\
\text { Inverno }\end{array}$ & 14.0 & 10.0 & 12.0 & $\begin{array}{l}\text { P5 (64.3) } \\
\text { P4 (28.6) } \\
\text { P3 (7.1) }\end{array}$ & 6.5 & 7.5 & $\begin{array}{l}\text { P10 (64.3) } \\
\text { P9 (28.6) } \\
\text { P11 (7.1) }\end{array}$ \\
\hline $\begin{array}{l}\text { Tardes } \\
\text { Verão }\end{array}$ & 12.0 & 6.0 & 6.0 & $\begin{array}{l}\text { P4 }(60.0) \\
\text { P3 }(40.0)\end{array}$ & 9.0 & 10.0 & $\begin{array}{l}\text { P10 }(60.0) \\
\text { P9 }(40.0)\end{array}$ \\
\hline
\end{tabular}

Mediana $H R>-H R<$ : mediana das diferenças de humidade relativa entre o local mais húmido e o local mais seco de todo o percurso de observação

Mediana [(HRSC-HR2)+(HRSC-HR6)]/2: mediana das médias das diferenças de humidade relativa entre o local mais húmido do Parque de Santa Cruz (HRSC) e a Rua Lourenço de Almeida Azevedo (HR2), ben como a Praça da República (HR6)

Mediana HRSCmáx.: mediana das máximas diferenças de humidade relativa entre o local mais húmido do Parque de Santa Cruz (HRSC) e a Rua Lourenço de Almeida Azevedo (HR2), bem como a Praça da República (HR6)

PSC HR>: locais do Parque de Santa Cruz com a humidade relativa mais elevada, por ordem decrescente de frequência de ocorrência, cujo valor relativo à amostra considerada, em percentagem. é apresentado entre parentesis

Mediana [(HRB-HR8) $+($ HRB-HR 12)]/2: mediana das nédias das diferenças de humidade relativa entre o local mais húmido do Jardim Botânico (HRB) e a Alameda Dr. Júlio Henriques (HR8), bem como a Praça D. Dinis (HR 12)

Mediana HRBmáx.: mediana das máximas diferenças de humidade relativa entre o local mais húmido Jardim Botânico (HRB) e a Alameda Dr. Júlio Henriques (HR8), bem como a Praça D. Dinis (HR 12)

PB HR>: locais do Jardim Botânico com a humidade relativa mais elevada, por ordem decrescente de frequência de ocorrência, cujo valor relativo à amostra considerada, em percentagem, é apresentado entre parentesis 
significativamente entre si e é maior no Inverno, tanto de manhã como de tarde, do que em tardes de Verão. Assim, os valores medianos da intensidade média da célula fresca do Parque de Santa Cruz e do Jardim Botânico são, em manhãs de Inverno, respectivamente, de $-0.9^{\circ} \mathrm{C}$ e $-1.5^{\circ} \mathrm{C}$, em tardes de Inverno de $-1.3^{\circ} \mathrm{C}$ e $-1.4^{\circ} \mathrm{C}$, e em tardes de Verão descem para $-0.6^{\circ} \mathrm{C}$ e $-0.7^{\circ} \mathrm{C}$. Os valores medianos da intensidade máxima destas células frescas são ligeiramente superiores: $-1.2^{\circ} \mathrm{Ce}-1.5^{\circ} \mathrm{C}$ nas manhãs de Inverno, $-1.7^{\circ} \mathrm{C}$ nas tardes de Inverno e $-0.7^{\circ} \mathrm{C}$ e $-1.2^{\circ} \mathrm{C}$ em tardes de Verão.

Relativamente aos locais dos espaços verdes onde a frequência de ocorrência de temperaturas mais baixas é maior, no caso do Jardim Botânico esta corresponde sempre ao ponto P10 (clareira ocupada por um lago), embora em tardes de Verão apareça com igual frequência o ponto P9 (povoamento arbóreo fechado).

No caso do Parque de Santa Cruz, tanto em manhãs como em tardes de Inverno, o local onde com maior frequência se observam as temperaturas mais baixas é P5 (grande densidade arbórea a cota mais baixa) e, nas tardes de Verão, P3 (grande densidade arbórea a cota mais alta). No ponto P4 (clareira ocupada por um lago), a frequência de ocorrência de temperaturas mais baixas é maior em manhãs de Inverno, em função da fraca ocultação do horizonte que facilita o arrefecimento nocturno e cujos efeitos se prolongam pelas primeiras horas da manhã. A frequência de ocorrência de temperaturas mais baixas, neste local, é pouco significativa em tardes de Inverno e especialmente em tardes de Verão, agora por atenuação do efeito de sombra neste espaço aberto. Este facto é corroborado pelo perfil da figura 4 , onde se pode observar que o efeito da clareira do Parque de Santa Cruz (P4), cuja influência térmica quase não se distingue relativamente ao restante espaço verde no Inverno, nas tardes de Verão manifesta-se por um valor mediano de temperatura $0.4^{\circ} \mathrm{C}$ a $0.6^{\circ} \mathrm{C}$ superior ao do espaço arborizado próximo.

$O$ efeito de sombra imposto pela morfologia urbana da "Alta" (P13) reflecte-se na diminuição das temperaturas medianas aí observadas (fig. 4), tanto no Inverno como no Verão, de manhã e de tarde.

As menores temperaturas da Praça do Comércio (P16) nas manhãs de Inverno evidenciam, certamente, a conjugação de um arrefecimento nocturno do ar por irradiação, mais acentuado do que nas estreitas ruas envolventes, por menor ocultação do horizonte, com um mais tardio aquecimento diurno do ar por efeito de sombra.

Comparando os valores medianos de temperatura da Praça da República (P6), com os da Praça João Paulo II (P7), tanto em manhãs de Inverno como nas tardes de Verão, os primeiros são um pouco inferiores aos segundos, o que poderá traduzir um (embora ligeiro) efeito térmico "à distância" do Parque de Santa Cruz.

Note-se que (fig. 4), se no Inverno os valores medianos das temperaturas relativas ao IGU do Jardim Botânico e do Parque de Santa Cruz são negativos, já nas tardes de Verão, o sinal positivo dos seus valores, embora inferiores aos do espaço urbano envolvente, revelam que estes espaços verdes são mais quentes do que a área do IGU, nesta altura do ano e do dia. Tal verifica-se, certamente porque, pela sua posição sobreelevada, esta área encontra-se menos abrigada das circulações sinópticas as quais, por advecção, minimizam os efeitos térmicos do saldo fortemente positivo do balanço radiativo local.

Os contrastes higrométricos espaciais ao longo do percurso de observação, evoluem em sentido inverso da temperatura, sendo as células frescas do Parque de Santa Cruz e do Jardim Botânico, simuitaneamente, células de humidade no contexto espacial em que se inserem (fig. 4).

Atendendo à totalidade do conjunto de pontos de observação, os maiores contrastes higrométricos medianos (quadro 4) ocorrem nas tardes de Inverno $(14 \%)$ e são ligeiramente superiores aos valores encontrados para as manhãs de Inverno (13\%) ou para as tardes de Verão (12\%).

A mediana da intensidade média da célula húmida do Parque de Santa Cruz é, no Inverno, maior do que a do Jardim Botânico. De manhã, os contrastes higrométricos entre estes espaços verdes e os locais do espaço urbano envolvente são de $10 \%$ para o Parque de Santa Cruz e de apenas $4 \%$ para o Jardim Botânico. No período da tarde são de $10 \%$ no caso do Parque de Santa Cruz e de $6.5 \%$ no caso do Jardim Botânico.

Nas tardes de Verão a relação inverte-se: a intensidade da célula húmida do Jardim Botânico (9\%) supera a do Parque de Santa Cruz (6\%).

Em qualquer dos casos e relativamente a ambos os espaços verdes, o valor mediano da intensidade máxima das células de humidade ultrapassa os valores anteriores em apenas $1 \%$.

O local do Parque de Santa Cruz onde, com maior frequência, ocorrem os valores mais elevados de humidade relativa é, em manhãs e tardes de Inverno, o P5 (denso povoamento arbóreo) em relação, certamente, com as menores temperaturas que aí mais frequentemente ocorrem. Já nas tardes de Verão é no local P4 (clareira ocupada por um lago) que com maior frequência se observam os mais elevados valores de humidade relativa, 3 a $4 \%$ superiores aos dos outros pontos do parque (fig. 4). Atendendo a que as temperaturas medianas deste local, em tardes de Verão, são ligeiramente superiores às do espaço 
arborizado próximo, a maior humidade relativa do ar aqui observada, nada terá a ver com a capacidade higrométrica do ar, mas sim com o efeito higrométrico da forte evaporação da água do lago.

Este facto não é evidente em relação ao lago de menores dimensões do Jardim Botânico (P10) uma vez que, embora seja neste local do espaço verde que com maior frequência ocorrem os mais elevados valores de humidade relativa (quadro 4), o mais elevado valor mediano de humidade relativa em tardes de verão (fig. 4) não corresponde a P10, mas ao local P9 (povoamento arbóreo fechado).

\section{A variação intradiurna}

Os perfis da figura 5 permitem observar a variação intradiurna do comportamento espacial das diferenças de temperatura e de humidade relativa, em relação ao IGU, num dos dias de Inverno da amostra (14.12.94), em que foi possível efectuar 5 percursos de medição - 2 no período da manhã e 3 durante a tarde - sob condições de tempo de céu limpo e vento fraco, de SSE durante a manhã, rodando para WNW durante a tarde. O último percurso de observação do dia foi já efectuado com condições de tempo diferentes: céu muito nublado e vento fraco de WSW.

O traçado das diferentes curvas térmicas e higrométricas, nos seus aspectos mais gerais, assemelhase entre si, correspondendo normalmente aos espaços verdes do Parque de Santa Cruz e do Jardim Botânico, os menores valores de temperatura e os maiores valores de humidade relativa, pelo menos em relação ao espaço urbanizado envolvente mais próximo.

Os contrastes térmicos e higrométricos do conjunto de todos os pontos de observação (quadros 6 e 7), não obstante diferenças de pormenor, foram semelhantes a diferentes horas do dia, variando entre $2.1{ }^{\circ} \mathrm{C}$ e $2.7^{\circ} \mathrm{C}$ no caso da temperatura, e $11 \%$ e $14 \%$ quanto à humidade relativa.

A intensidade da célula fresca do Jardim Botânico foi sempre, ao longo de todo o dia, maior do que a do Parque de Santa Cruz, o mesmo acontecendo relativamente à intensidade da célula de humidade relativa, excepto no caso da primeira observação matinal, em que a célula húmida do Parque de Santa Cruz superou ligeiramente a do Jardim Botânico.
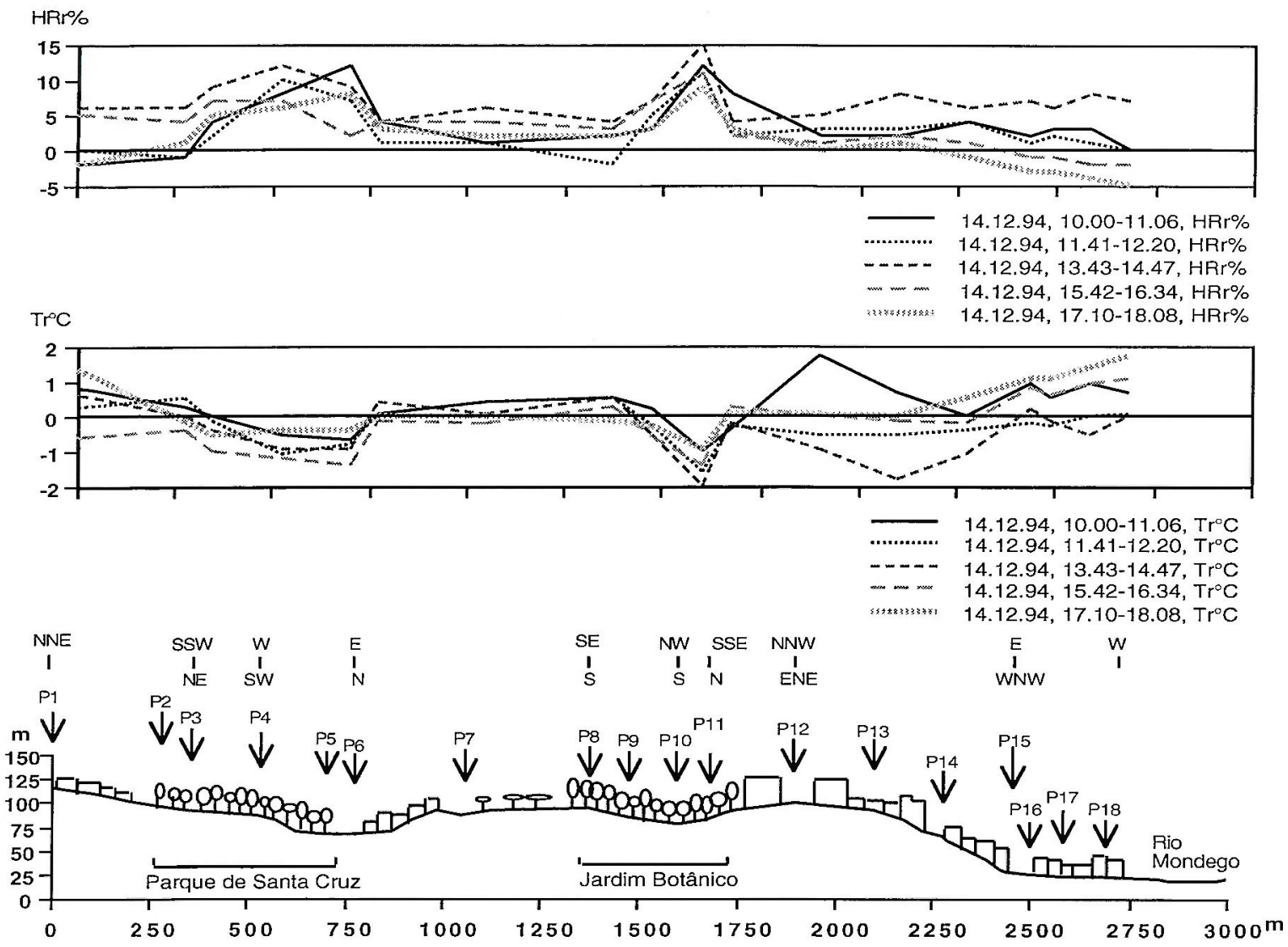

Fig. 5 - Perfis das diferenças de temperatura $\left(\mathrm{Tr}^{\circ} \mathrm{C}\right)$ e de humidade relativa (HRr\%), relativas ao IGU, a diferentes horas de um dia da amostra (14.12.94) 
Quadro 5

Contrastes térmicos a diferentes horas de um dia da amostra (14.12.94)

\begin{tabular}{|c|ccccccc|}
\hline 14.12 .94 & $\mathrm{~T}>-\mathrm{T}<$ & {$[(\mathrm{TSC}-\mathrm{T} 2)+(\mathrm{TSC}-\mathrm{T} 6)] / 2$} & TSCmax. & PSC T< & {$[(\mathrm{TB}-\mathrm{T} 8)+(\mathrm{TB}-\mathrm{T} 12)] / 2$} & TBmax. & PB T< \\
\hline 10.00 & 2.7 & -0.9 & -1.0 & $\mathrm{P} 5$ & -2.1 & -2.7 & $\mathrm{P} 10$ \\
11.41 & 2.1 & -1.4 & -1.6 & $\mathrm{P} 4$ & -1.6 & -2.1 & $\mathrm{P} 10$ \\
13.43 & 2.6 & -1.1 & -1.3 & $\mathrm{P} 4, \mathrm{P} 5$ & -1.9 & -2.5 & $\mathrm{P} 10$ \\
15.42 & 2.5 & -1.2 & -1.3 & $\mathrm{P} 5$ & -1.6 & -1.7 & $\mathrm{P} 10$ \\
17.10 & 2.6 & -0.5 & -0.5 & $\mathrm{P} 3$ & -0.9 & -1.0 & $\mathrm{P} 10$ \\
\hline
\end{tabular}

T> - T<: diferença de temperatura entre o local mais quente e o local mais fresco de todo o percurso de observação

[(TSC-T2)+(TSC-T6)]/2: média das diferenças de temperatura entre o local mais fresco do Parque de Santa Cruz (TSC) e a Rua Lourenço de Almeida Azevedo (T2), bem como a Praça da República (T6)

TSCmáx.: máxima diferença de temperatura entre o local mais fresco do Parque de Santa Cruz (TSC) e a Rua Lourenço de Almeida Azevedo (T2), bem como a Praça da República (T6)

PSC T<: local do Parque de Santa Cruz com a temperatura mais baixa

[(TB-T8)+(TB-T12)]/2: mediana das médias das diferenças de temperaiura entre o local mais fresco do Jardim Botânico (TB) e a Alameda Dr. Júlio Henriques (T8), bem como a Praça D. Dinis (T12)

TBmáx.: máxima diferença de temperatura entre o local mais fresco do Jardim Botânico(TB) e a Alameda Dr. Júlio Henriques (T8), bem como a Praça D. Dinis (T12)

$\mathrm{PB} T<$ : Iocal do Jardim Botânico com a temperatura mais baixa

Quadro 6

Contrastes higrométricos a diferentes horas de um dia da amostra (14.12.94)

\begin{tabular}{|c|ccccccc|}
\hline 14.12 .94 & HR $>$ HR $<$ & (HRSC-HR2)+(HRSC-HR6)]/2 & HRSCmax. & PSC HR $>$ & {$[($ HRB-HR8)+(HRB-HR 12) $/ 2$} & HRBmax. & PB HR $>$ \\
\hline 10.00 & 14 & 11 & 13 & P5 & 10 & 10 & P10 \\
11.41 & 13 & 10 & 11 & P4 & 11 & 13 & P10 \\
13.43 & 11 & 7 & 8 & P4 & 11 & 11 & P10 \\
15.42 & 13 & 3 & 3 & P3, P4 & 9 & 10 & P10 \\
17.10 & 14 & 6 & 7 & P5 & 8 & 9 & P10 \\
\hline
\end{tabular}

$H R>-H R<$ : diferença de humidade relativa entre o local mais húmido e o local mais seco de todo o percurso de observação [(HRSC-HR2)+(HRSC-HR6)]/2: mediana das médias das diferenças de humidade relativa entre o local mais húmido do Parque de Santa Cruz (HRSC) e a Rua Lourenço de Almeida Azevedo (HR2), bem como a Praça da República (HR6)

HRSCmáx.: máxima diferença de humidade relativa entre o local mais húmido do Parque de Santa Cruz (HRSC) e a Rua Lourenço de Almeida Azevedo (HR2), bem como a Praça da República (HR6)

PSC HR>: local do Parque de Santa Cruz com a humidade relativa mais elevada

[(HRB-HR8)+(HRB-HR 12)]/2: mediana das médias das diferenças de humidade relativa entre o local mais húrnido do Jardim Botânico (HRB) e a Alameda Dr. Júlio Henriques (HR8), bem como a Praça D. Dinis (HR12)

HRBmáx.: máxima diferença de humidade relativa entre o local mais húmido Jardim Botânico (HRB) e a Alameda Dr. Júlio Henriques (HR8), bem como a Praça D. Dinis (HR 12)

PB HR >: local do Jardim Botânico com a humidade relativa mais elevada

Noentanto, os valores encontrados não evidenciam um comportamento linear no ritmo intradiurno dos contrastes termohigrométricos entre os espaços verdes e o espaço urbano envolvente. Em qualquer dos casos, a menor intensidade das células de frescura e de humidade observou-se ao fim da tarde, com valores de $-0.5^{\circ} \mathrm{C}$ e $6 \%$ no Parque de Santa Cruz e de $-0.9^{\circ} \mathrm{C}$ e $8 \%$ no Jardim Botânico, em relação provável com a alteração das condições de tempo verificada a esta hora. A forte nebulosidade atenuou o efeito termohigro- 
métrico local dos espaços verdes, mas os valores dos contrastes espaciais de todo o conjunto dos locais de observação não se ressentiram da modificação das condições atmosféricas, sendo semelhantes aos verificados a outras horas do dia, com céu limpo.

Da observação dos perfis da figura 5 pode-se concluir que na origem destes contrastes estão as mais elevadas temperaturas e as mais baixas humidades relativas da "Baixa" em relação ao restante espaço contemplado nos percursos de observação, manifestação do núcleo principal da ilha de calor de Coimbra (GANHO, 1992a, 1992b, 1995a, 1995b), ainda não inibido pela nebulosidade, provavelmente devido aos efeitos térmicos, no espaço urbanizado, de um dia de forte insolação.

A maior intensidade média da célula de frescura do Parque de Santa Cruz verificou-se ao fim da manhã $\left(-1.4^{\circ} \mathrm{C}\right)$, assim como a sua intensidade máxima $\left(-1.6^{\circ} \mathrm{C}\right)$, embora os valores correspondentes ao início e meio da tarde não difiram significativamente destes.

No caso da célula de frescura do Jardim Botânico, tanto a intensidade média como a intensidade máxima tiveram a sua maior expressão ao início da manhã, com valores de $-2.1^{\circ} \mathrm{C} \mathrm{e}-2.7^{\circ} \mathrm{C}$ respectivamente, $\mathrm{e}$ um máximo secundário ao início da tarde, de $-1.9^{\circ} \mathrm{C}$ e $-2.5^{\circ} \mathrm{C}$.

Relativamente à intensidade média das células de humidade relativa, no caso do Parque de Santa Cruz, os maiores valores matinais $(11$ a $10 \%)$ foram-se atenuando ao longo do dia ( $7 \%$ ao início da tarde e $3 \%$ a meio da tarde), intensificando-se novamente ao fim da tarde $(6 \%)$. No caso do Jardim Botânico, a uma intensidade estável durante a manhã e início da tarde (10 a $11 \%$ ), verificou-se uma ligeira atenuação no decurso da tarde ( 9 a $8 \%$ ).

Tanto em relação ao Parque de Santa Cruz como ao Jardim Botânico, o comportamento intradiurno da intensidade máxima das células de humidade obedeceu ao mesmo ritmo, mas com valores 1 a $2 \%$ superiores.

O local mais fresco e mais húmido do Jardim Botânico foi, a qualquer hora do dia, PIO (clareira ocupada por um lago).

No Parque de Santa Cruz, na l a observação matinal, a temperatura mais baixa e a humidade relativa mais elevada observaram-se simultaneamente em P5 (povoamento arbóreo fechado). A meio da manhã o ponto mais fresco e húmido foi P4 (clareira ocupada por um lago), assim como ao início da tarde, cmbora a esta hora P5 registasse a mesma temperatura que P4 mas menos humidade relativa que este. A meio da tarde o local mais fresco (novamente P5), não coincidia com aqueles em que a humidade relativa era mais elevada (P3 e P4), o mesmo se verificando ao fim da tarde, em que o local mais fresco foi P3 (vegetação arbórea densa) e o mais húmido P5.
É interessante verificar que (fig. 5), a influência da morfologia urbana, por intermédio do efeito de sombra que determina, nas temperaturas das ruas estreitas da "Alta", se assemelhou, em magnitude, ao efeito térmico dos espaços verdes, uma vez que as temperaturas relativas aqui observadas a esta hora, eram semelhantes às do Jardim Botânico e, inclusivamente, inferiores às do Parque de Santa Cruz. Os valores de humidade relativa desta área da cidade reflectiam o mesmo efeito, embora não sendo tão elevados como os registados nos espaços verdes, onde a evapotranspiração contribuia certamente para um maior enriquecimento do ar em vapor de água do que no espaço construído da "Alta", onde era somente a menor temperatura, sinónimo de menor capacidade higrométrica do ar, a explicar o aumento da humidade relativa.

\section{A influência das condições de tempo}

Os perfis da figura 6 permitem comparar a variação espacial da humidade relativa e da temperatura, relativas ao IGU, para diferentes condições de tempo. Os dados correspondem a duas tardes de Inverno, sensivelmente à mesma hora, uma delas com céu muito nublado e vento moderado (29.11.94), a outra com céu limpo e vento fraco (12.12.94).

$\mathrm{O}$ aspecto que mais se salienta, e que corrobora o que seria de esperar, é o de uma nítida atenuação dos contrastes termohigrométricos espaciais associados aos espaços verdes em situaçōes de forte nebulosidade e vento moderado, relativamente ao que acontece com condições de céu limpo e vento fraco. Tal atenuação, no entanto, não é tão significativa relativamente aos contrastes observados para a totalidade dos diferentes pontos do espaço construído que, entre um e outro dia, apresentaram valores semelhantes.

Assim, sob condições de céu limpo e vento fraco, as diferenças termohigrométricas encontradas ao longo de todo o percurso foram, respectivamente, de $3.1^{\circ} \mathrm{C}$ e $15 \%$, muito próximas dos $2.7^{\circ} \mathrm{C}$ e $14 \%$ correspondentes a condições de tempo nublado e vento moderado (quadros 7 e 8 ).

No entanto, a intensidade da célula fresca do Parque de Santa Cruz foi, na presença de nebulosidade e vento, ligeiramente atenuada $\left(-1.3^{\circ} \mathrm{C}\right)$ relativamente à situação de céu limpo e vento fraco $\left(-1.7^{\circ} \mathrm{C}\right)$. Este facto é muito mais nítido no caso da célula fresca do Jardim Botânico que, na tarde nublada apresentou uma intensidade média de $-0.9^{\circ} \mathrm{C}$ (inferior até à do Parque de Santa Cruz) e, na ausência de nebulosidade e vento significativo, se intensificou para $-2.7^{\circ} \mathrm{C}$.

As células de humidade relativa apresentaram um comportamento semelhante, mas em sentido inverso aos valores da temperatura. Na tarde de céu muito nublado e vento moderado, a intensidade média das células de frescura do Parque de Santa Cruz e do 


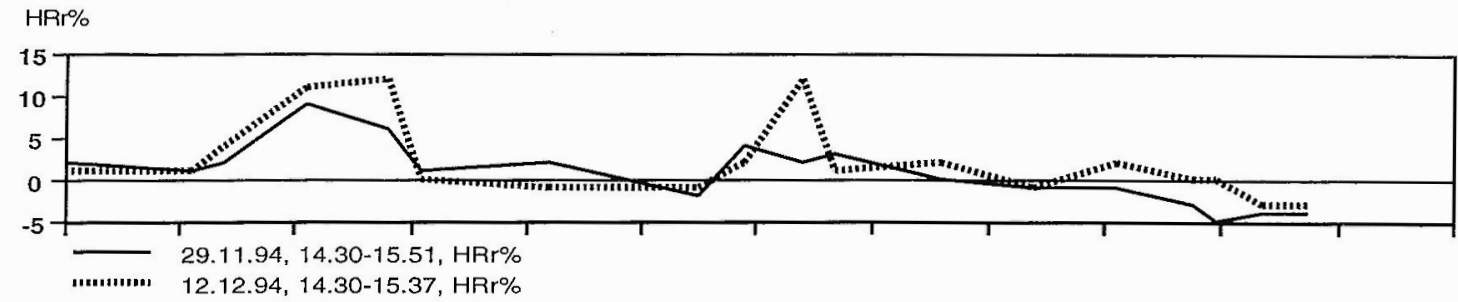

$\operatorname{Tr} \mathrm{C}$

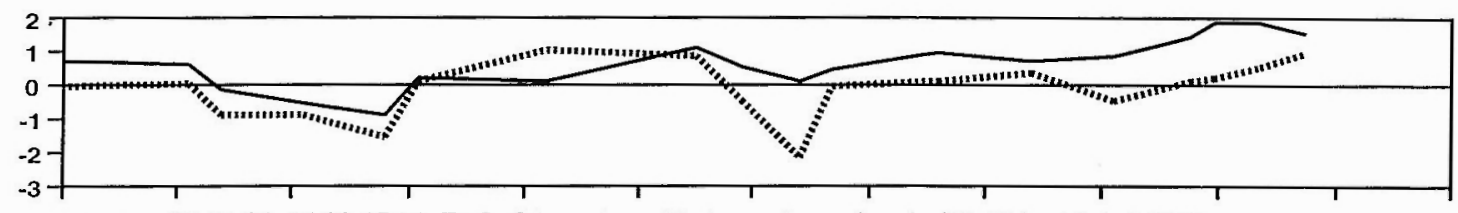

- 29.11.94, 14.30-15.51, $\operatorname{Tr}^{\circ} \mathrm{C}$, Céu muito nublado, vento moderado $(28-18 \mathrm{~km} / \mathrm{h})$ de ESE/E

"un!" 12.12.94, 14.30-15.37, Tro C, Céu limpo, vento fraco $(7-9 \mathrm{~km} / \mathrm{h})$ de SE/ESE

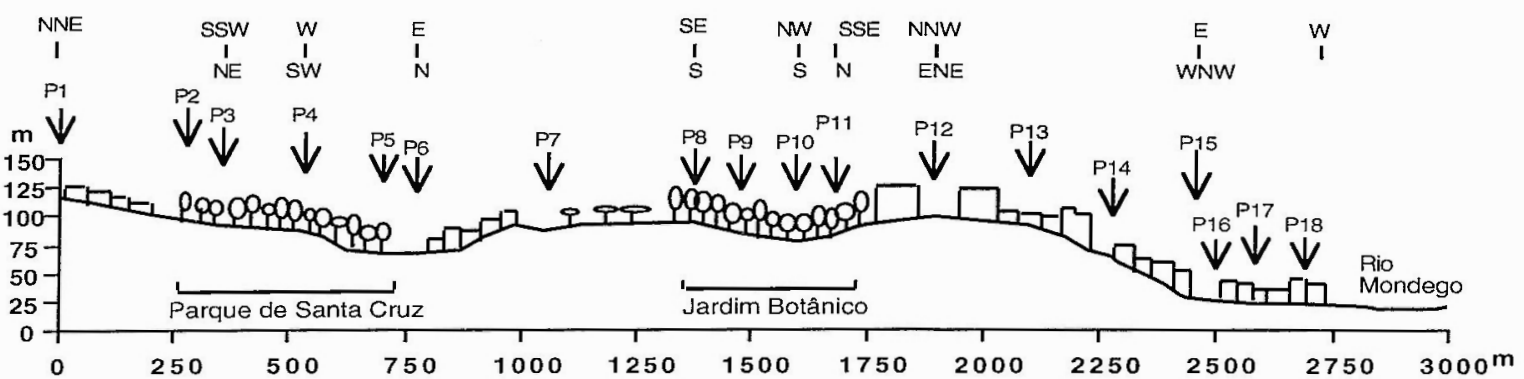

Fig. 6 - Perfis das diferenças de temperatura ( $\mathrm{Tr}^{\circ} \mathrm{C}$ ) e de humidade relativa (HRr\%), relativas ao IGU, em dois dias da amostra (29.11.94 e 12.12.94), com diferentes condiçōes de tempo

Quadro 7

Contrastes tếrmicos com diferentes condições de tempo

\begin{tabular}{|c|ccccccc|}
\hline & T $>-T<$ & {$[(T S C-T 2)+(T S C-T 6)] / 2$} & TSCmax. & PSC T< & (TB-T8)+(TB-T12)]/2 & TBmax. & PB T< \\
\hline 29.11 .94 & 2.7 & -1.3 & -1.5 & P5 & -0.9 & -1.0 & P 10 \\
12.12 .94 & 3.1 & -1.7 & -1.7 & P5 & -2.7 & -3.0 & P10 \\
\hline
\end{tabular}

LEGENDA: a mesma do quadro 5

29.11.94: Céu muito nublado, vento moderado

12.12.94: Céu limpo, vento fraco

Quadro 8

Contrastes higrométricos com diferentes condições de tempo

\begin{tabular}{|l|ccccccc|}
\hline & HR $>$-HR $<$ & (HRSC-HR2)+(HRSC-HR6) $) / 2$ & HRSCmax & PSC HR $>$ & I(HRB-HR8)+(HRB-HR 12) $/ 2$ & HRBmax. & PB HR> \\
\hline 29.11 .94 & 14 & 8 & 8 & P4 & 5 & 6 & P9 \\
12.12 .94 & 15 & 12 & 12 & P5 & 12 & 13 & P10 \\
\hline
\end{tabular}

LEGENDA: a mesma do quadro 6

29.11.94: Céu muito nublado, vento moderado

12.12.94: Céu limpo, vento fraco 
Jardim Botânico era de 8 e 5\% respectivamente, tendo-se acentuado para $12 \%$ em ambos os casos na situação em que vigoravam condições de céu limpo e vento fraco.

Considerando-se a intensidade máxima das células de frescura e de humidade destes espaços verdes, os seus valores comportam-se exactamente da mesma maneira entre um e outro dos dias analisados, diferindo da intensidade média apenas em 2 ou 3 décimas de grau para baixo no caso das temperaturas e em 1 ou 2 unidades percentuais para cima no caso da humidade relativa.

Nos dois dias de observação as temperaturas mais baix as de cada um dos espaços verdes registaramse sempre nos mesmos locais: P5 no caso do Parque de Santa Cruz e P10 no caso do Jardim Botânico.

Sob condições atmosféricas de céu limpo e vento fraco, os locais mais húmidos correspondiam aos mais frescos, mas na tarde de tempo nublado e vento, os locais onde se observaram os maiores valores de humidade relativa foram, P4 no Parque de Santa Cruz e P9 no Jardim Botânico. Tratando-se P4 de uma clareira ocupada por um lago é natural que a maior humidade do ar seja a manifestação do efeito higrométrico da evaporação da água do lago por acção da radiação directa incidente.

É interessante verificar que, a par da minimização dos efeitos topoclimáticos dos espaços verdes por acção conjugada de nebulosidade e vento, se observou, nesta situação, um reforço dos contrastes termohigrométricos espaciais entre a "Baixa" (mais quente e seca) e o restante espaço contemplado nos percursos de observação. Este facto justifica a semelhança nos valores dos contrastes de temperatura e humidade relativa, encontrados para a totalidade dos pontos de observação, entre as duas situações analisadas, não obstante a atenuação das células frescas e húmidas associadlas aos espaços verdes.

Note-se ainda que foi sob condições de forte nebulosidade e vento que as diferenças (positivas) de temperatura do espaço construído, relativamente ao IGU, se revelaram mais significativas, provavelmente por atenuação do efeito de sombra e aumento da radiação difusa, a qual mais facilmente transpõe o obstáculo da ocultação do horizonte. O mesmo efeito poderá conjugar-se com uma diminuição do fluxo de calor latente em favor do fluxo de calor sensível, por inibição da evapotranspiração na ausência de radiação solar directa, para a explicação dos efeitos termohigrométricos da nebulosidade no espaço dos fustes.

\subsection{Efeitos bioclimáticos do Parque de Santa Cruze do Jardim Botânico}

Sendo as sensações de conforto ou desconforto do organismo humano determinadas por combinações de variáveis climáticas, nomeadamente da temperatura e da humidade relativa, a influência termohigrométrica dos espaços verdes e os contrastes topoclimáticos que estes determinam, vão determinar também contrastes espaciais dos índices de desconforto bioclimático, como o índice de temperatura-humidade (ITH).

Os perfis da figura 7 evidenciam bem este facto. Numa tarde de Verão (8.6.95), o efeito conjugado da temperatura com a humidade relativa determinava valores de ITH, no IGU e em grande parte do espaço percorrido ao longo da campanha de observação, superiores a 21 , testemunhando uma ambiência atmosférica desconfortável para uma percentagem razoável de indivíduos.

No entanto, não obstante o aumento dos valores de humidade relativa observados no Parque de Santa Cruz, a simultânea diminuição da temperatura fazia-lhe corresponder valores de ITH muito próximos de 21, ou seja, uma ambiência atmosférica com menor grau de desconforto, com expressão também no espaço envolvente, nomeadamente na Praça da República (P6), por efeito "à distância" deste espaço verde.

No Jardim Botânico, porque a sua influência termohigrométrica não se manifestava, nesta tarde, de forma tão significativa como no caso do Parque de Santa Cruz, os valores de ITH superavam os observados aqui .

É de assinalar que o efeito térmico do efeito de sombra imposto pela morfologia urbana da "Alta", conjugado com a maior secura do ar, determinava valores de ITH iguais ou inferiores a 21 e, até, inferiores aos verificados no Parque de Santa Cruz, fazendo desta área da cidade a mais aprazível, do ponto de vista bioclimático, do conjunto de locais contemplados no percurso de observação. Já na "Baixa", e nomeadamente na Praça do Comércio (P16), onde o efeito de sombra a esta hora de um dia de Verão assume pouca importância espacial, as temperaturas mais elevadas faziam subiro ITH para valores superiores a 21 , assim aumentando o desconforto.

Os perfis da figura 8 , referentes a outra tarde de Verão (11.6.95), sensivelmente à mesma hora, revelam um comportamento espacial do ITH diferente do caso anterior.

Tanto no IGU como na quase totalidade do espaço observado o valor de ITH era superior a 21 . Mas agora, a diminuição da temperatura observada no interior do Parque de Santa Cruz e no Jardim Botânico, se por si só poderia contribuir para uma diminuição do desconforto bioclimático, porque combinado com um significativo aumento da humidade relativa do ar, traduziu-se por um aumento do ITH e consequentemente num agravamento das condições de desconforto, particularmente sensível nas clareiras do Parque de Santa Cruz (P4) e do Jardim Botânico (P10). 
ITH
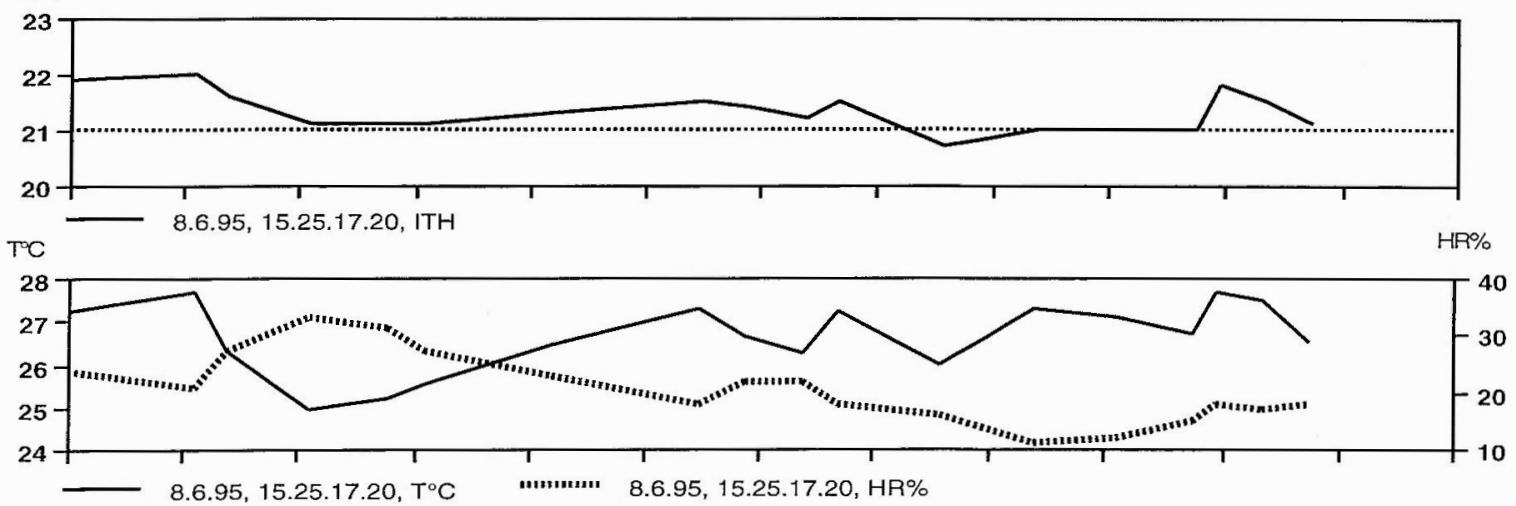

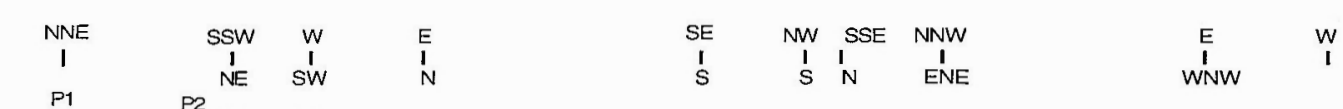

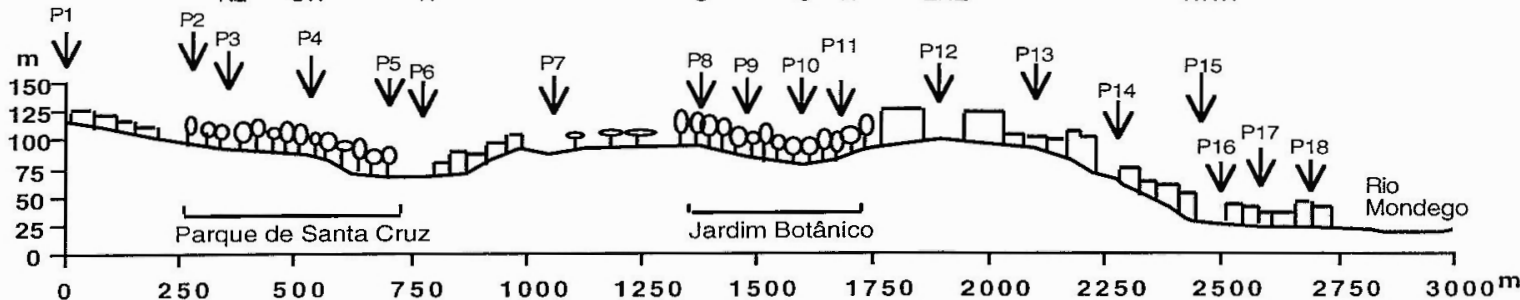

Fig. 7 - Perfis de temperatura $\left(\mathrm{T}^{\circ} \mathrm{C}\right.$ ), de humidade relativa (HR\%), e do índice de temperatura-humidade (ITH), num dia de Verão (8.6.95)
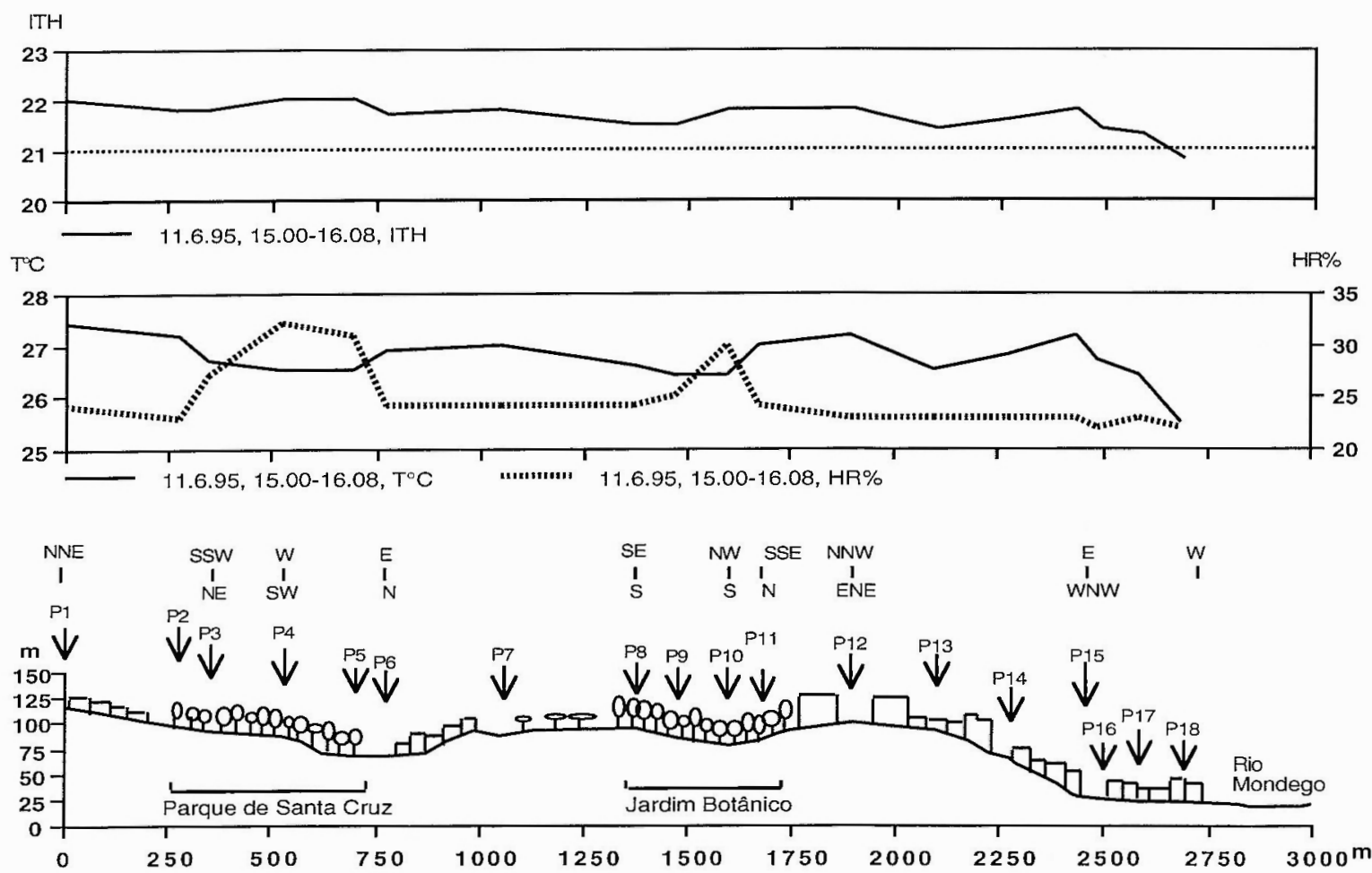

Fig. 8 - Perfis de temperatura $\left(\mathrm{T}^{\circ} \mathrm{C}\right.$ ), de humidade relativa (HR\%), e do índice de temperatura-humidade (ITH), num dia de Verão (11.6.95) 
O mesmo tipo de situação é evidenciada pelos perfis da figura 9, referentes a uma campanha de observação efectuada noutra tarde estival (15.6.95), em que novamente o valor de ITH no IGU era superior a 21 .

A distribuição dos valores do ITH no interior do Parque de Santa Cruz revelava apreciáveis contrastes, nomeadamente entre os espaços arborizados fechados (P3 e P5) e a clareira (P4). Nos primeiros a frescura do ar era o factor determinante na descida do ITH para próx imo do limiar de 21 ou abaixo. Na clareira, a subida da temperatura imposta pela ausência do efeito de sombra, conjugada com humidade relativa tão elevada como no espaço dos fustes do povoamento fechado e mais elevada do que no espaço construído, assegurava para este local o mais elevado valor do ITH de todo o espaço percorrido ao longo da campanha de observação.

No Jardim Botânico, a descida da temperatura, menos significativa do que no Parque de Santa Cruz e porque conjugada com valores de humidade relativa idênticos ao deste espaço verde, não foi suficiente para aproximar de $21 \mathrm{o}$ ITH. Embora aqui os contrastes espaciais das variáveis observadas não fossem acentuados, nem consequentemente os correspondentes valores do ITH, foi também na clareira (P10) ocupada por um lago que a humidade relativa era mais elevada e onde, consequentemente, a ambiência atmosférica se tornava menos confortável.

Na explicação dos factos observados relativamente às clareiras destes espaços verdes, poderá em parte estar o efeito higrométrico dos lagos que nelas se encontram e que, assim, em algumas situações, contribuirão certamente para um agravamento das condições de desconforto bioclimático.

Nesta tarde, o ITH dos locais de observação da "Alta" e da "Baixa" oscilava entre valores inferiores a 21 nas ruas estreitas (P13, P15, P17 e P18) e superiores a 21 nos locais de menor ocultação do horizonte - Largo da Sé Velha (P14) e Praça do Comércio(P16) - revelando uma vez mais a importância do efeito térmico do efeito de sombra na ambiência atmosférica do ponto de vista bioclimático.
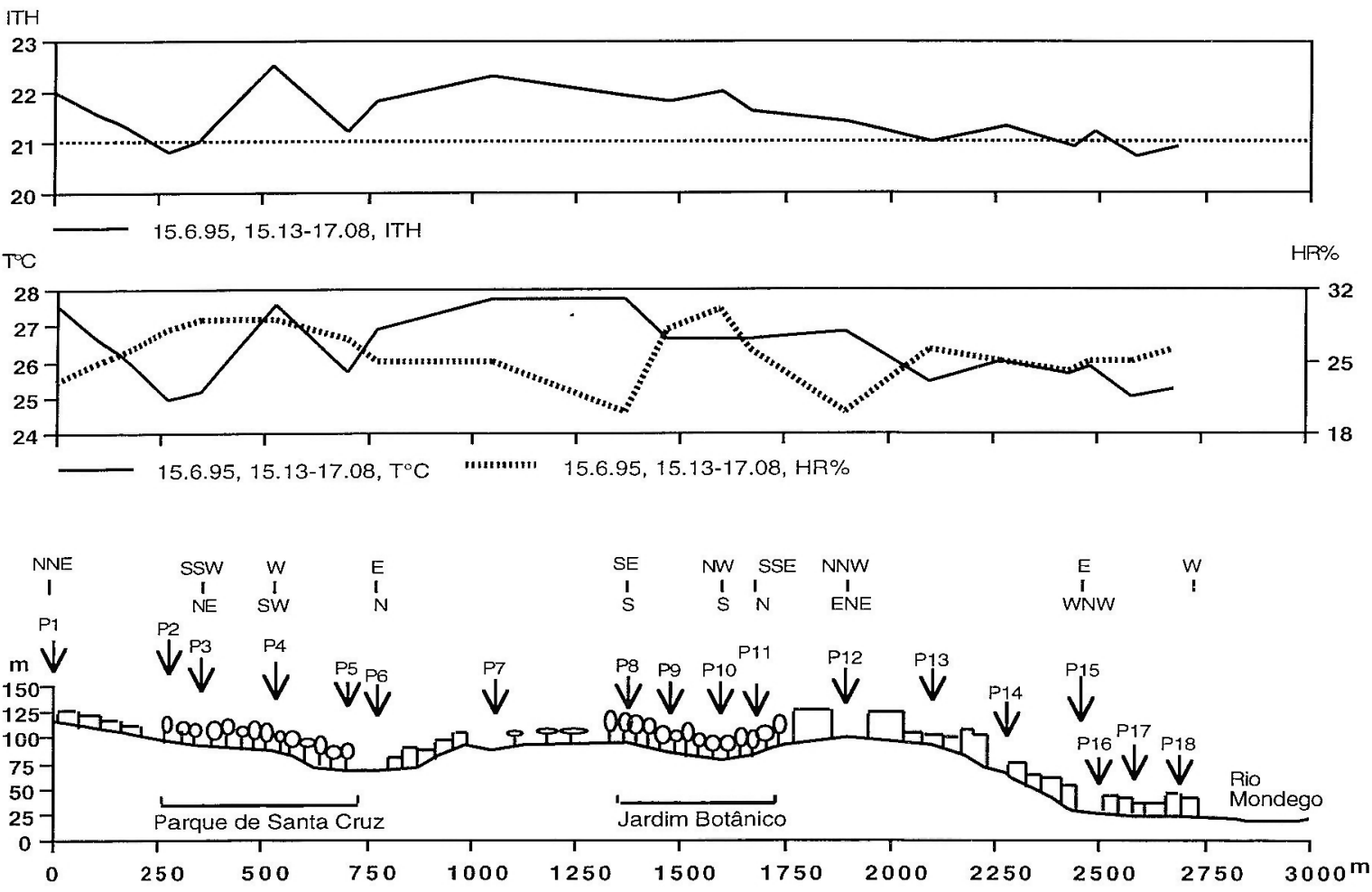


\section{Discussão}

\section{Efeito do Parque de Santa Cruz e do Jardim} Botânico nos riscos de poluição

Os espaços verdes, constituindo então células frias no interior do tecido urbano, induzem circulações atmosféricas de carácter mais ou menos localizado, determinadas pela sua influência térmica e condicionadas pela topografia. Os seus efeitos sobre os riscos de poluição do ar, variáveis de acordo com o contexto topográfico e com a morfologia urbana em que se inserem, exigem uma análise cuidada de cada caso de "per si".

A discussão que em seguida se faz sobre os possíveis efeitos do Jardim Botânico e do Parque de Santa Cruz nos riscos locais de poluição atmosférica, de carácter essencialmente teórico-dedutivo, alicerçase nas informações analisadas nos pontos anteriores sobre a sua influência termohigrométrica e nas observações empíricas efectuadas quase diariamente sobre aspectos da circulação local do ar, deduzidas pelo seu efeito instantâneo nas árvores ou bandeiras e pelo movimento de fumos ou de nevoeiro.

Tanto o Parque de Santa Cruz como o Jardim Botânico constituem fontes de ar frio cuja localização, na bacia de recepção de um vale, no $1^{\circ}$ caso, e num valeiro de declive acentuado perpendicular ao vale do Mondego, no $2^{\circ}$ caso, fomenta a drenagem do ar ao longo destas formas de relevo. Este processo ocorre especialmente durante a noite e em noites de céu limpo e vento fraco, em que a estratificação térmica estável da camada superficial da atmosfera o permite, já que durante o dia a instabilidade superficial e a termoconvecção por ela induzida, bem como as circulações de carácter sinóptico, sobrepõem os seus efeitos às circulações térmicas locais induzidas pelos contrastes espaciais de temperatura e pela topografia, inibindo-as.

No caso particular do Jardim Botânico, o arrefecimento nocturno do ar acima da superfície activa das copas, pressuporia o seu escoamento lento ao longo do valeiro em que está inserido e posterior acumulação à saída da forma de relevo, ou seja, por sobre a Av. Emídio Navarro e o Parque Dr. Manuel Braga, fomentando aí a criação ou reforço de inversões térmicas superficiais inibidoras da dispersão de poluentes emitidos pelo intenso tráfego automóvel que percorre esta artéria.

No entanto, este processo parece não se verificar. Com efeito, durante as noites de céu limpo, forte estabilidade vertical da baixa atmosfera e circulações sinópticas lentas, independentemente da sua direcção dominante, o vale do Mondego, frente à cidade, constitui um canal preferencial de drenagem do ar proveniente de áreas a montante da cidade, criando um fluxo de SE, com uma velocidade que se situa em torno do grau 2 ou 3 da escala de Beaufort (fig. 10). Este fluxo é evidenciado pela orientação das bandeiras na ponte de Santa Clara e também, em noites e madrugadas a que the corresponde um banco de nevoeiro restringido ao vale do Mondego, pela movimentação do nevoeiro, muito nítida quando observada a partir de pontos altos da área envolvente. A dimensão vertical e a fisionomia destes bancos de nevoeiro permitem deduzir a espessura, que

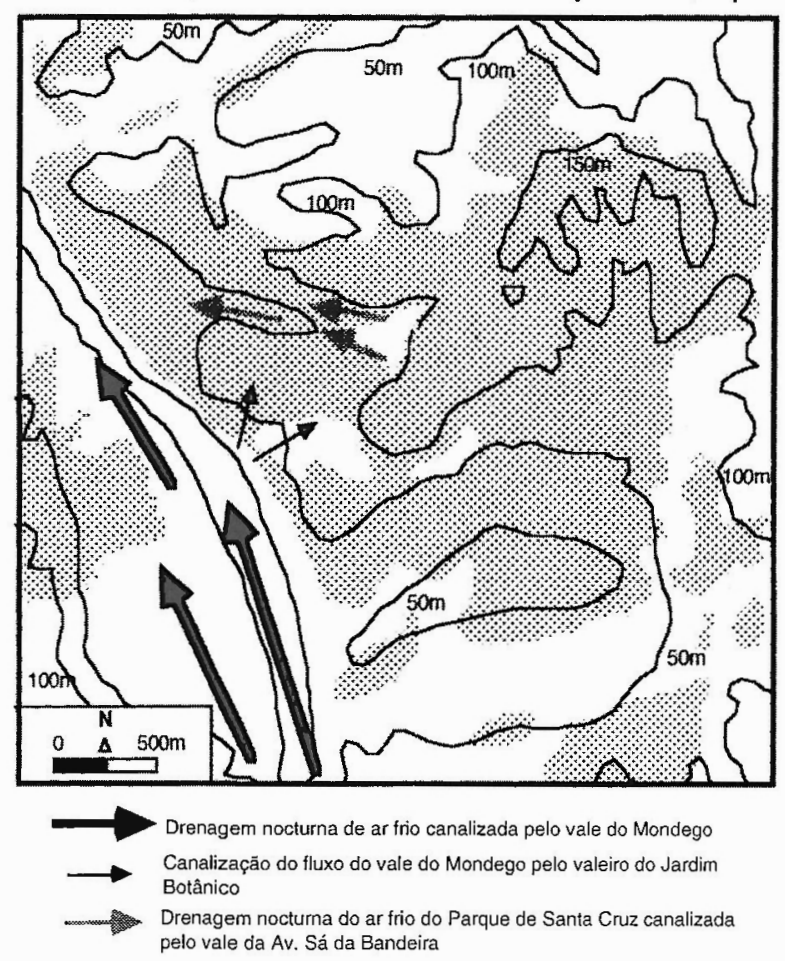

Fig. 10 - Aspectos da circulaçäo local do ar em noites e madrugadas sem nebulosidade e com circulação sinóptica lenta

frequentemente ultrapassa os $100 \mathrm{~m}$, e o carácter do fluxo, nomeadamente o escoamento turbulento por atrito com o solo, traduzido pelo aspecto cumuliforme do seu topo.

Esta circulação nocturna do ar ao longo do vale do Mondego, impõe-se a qualquer tipo de circulação muito localizada induzida pelo efeito térmico do Jardim Botânicoe, em vez de se verificar um escoamento catabático do ar orientado pelo valeiro que ocupa, o que ocorre é uma circulação ascendente ao longo da forma, manifestação de um ramo do fluxo do vale do Mondego orientado pela topografia. Estefluxocontribui para uma constante renovação nocturna do ar nas áreas da cidade marginais ao Mondego e para uma dispersão vertical dos poluentes, assegurada pela turbulência dinâmica. Mas, quer pela topografia, quer pela morfologia urbana, a sua penetração no "canopy-layer" da "Baixa" é dificultada, pouco se fazendo sentir. 
No caso do Parque de Santa Cruz a situação é diferente. Isolado pelo seu contex to topográfico dos efeitos advectivos, quer dos fluxos nocturnos drenados pelo vale do Mondego, quer de fluxos catabáticos que se manifestam frequentemente nos sectores leste e sul da cidade (GANHO, 1992a, 1995a, 1995b), estão criadas as condições fomentadoras de circulações de carácter localizado, restringidas à forma que ocupam e induzidas pelo espaço verde (fig. 10).

Assim, o ar arrefecido durante a noite acima da superfície activa das copas tem tendência a escoar lentamente ao longo do vale da Av. Sá da Bandeira em direcção à "Baixa". Isto mesmo pôde ser frequentemente confirmado, observando, a partir de um ponto alto sobranceiro à Praça da República, o comportamento de fumos ou pequenos bancos de nevoeiro ao início de manhãs de céu limpo e vento fraco. A disposição destas suspensões, em fino estrato cobrindo o Parque de Santa Cruz e deslizando lentamente por cima da Praça da República, testemunha a existência de uma estratificação térmica vertical do ar, estável, que dificulta a dispersão de poluentes, e uma circulação lenta orientada pela disposição do vale e pelo declive do terreno. Para estes fenómenos contribui certamente a localização do efeito térmico do espaço verde do Parque de Santa Cruz na bacia de recepção da forma.

As repercursões deste tipo de circulação local sobre os riscos de poluição atmosférica são discutíveis.

Por um lado, é estabelecida uma corrente de ar "limpo" ao longo do vale da Av. Sá da Bandeira em direcção à "Baixa" que, assegurando uma constante renovação doar, não obstante se processar sob condições nítidas de inversão térmica, facilita a dispersão de poluentes.

Por outro lado, a ocupação urbana, quer das vertentes quer do fundo do vale, bem como a disposição dos imóveis na parte terminal do vale - justapostos, em alinhamento perpendicular ao talvegue - por atrito dificulta a livre circulação do ar no "canopylayer" e na camada atmosférica imediatamente acima dele, contribuindo para a intensificação da magnitude das inversões térmicas, o que dificulta a dispersão de poluentes, assim aumentando localmente os riscos de poluição atmosférica de uma área sujeita a intenso tráfico automóvel.

Então, os efeitos térmicos do Parque de Santa Cruz e as circulações locais por eles induzidas, atendendo ao contexto topográfico e à morfologia urbana do espaço em que se insere, podem repercutirse "à distância" numa intensificação dos riscos locais de poluição atmosférica.

A sua confirmação científica exigiria um estudo de pormenor envolvendo, para além de recolha de dados no terreno, o recurso à modelização numérica e à simulação experimental.

\section{Conclusão}

Os resultados apresentados neste trabalho evidenciam uma nítida influência termohigrométrica dos espaços verdes, mesmo tratando-se de espaços verdes de dimensões modestas, criando contrastes espaciais de temperatura e de humidade relativa, em relação ao espaço urbano em que se inserem.

Estes contrastes espaciais, particularmente sensíveis sob condições de tempo de fraca nebulosidade e vento fraco, são mais significativos no Inverno do que no Verão e no Inverno mais acentuados durante a manhã do que durante a tarde. Entre o Parque de Santa Cruz e o Jardim Botânico, os efeitos topoclimáticos do segundo são mais significativos, em relação provável com a sua maior dimensão espacial.

Em contraste com os espaços verdes, os espaços abertos, como as praças, apresentam temperaturas mais elevadas, durante a tarde, por atenuação do efeito de sombra. É este efeito que justifica uma influência da morfologia urbana na diminuição das temperaturas diurnas, tão ou mais acentuada em ruas de forte ocultação do horizonte como as da "Alta" de Coimbra, do que a influência dos espaços verdes.

Estas influências topoclimáticas têm consequências na ambiência atmosférica, do ponto de vista bioclimático, variáveis de acordo com as condições atmosféricas dominantes. Se situações há, no Verão, em que a diminuição da temperatura que determinam se traduz realmente num aumento do conforto bioclimátco, noutras situações o simultâneo e consequente aumento da humidade relativa traduzse efectivamente numa ambiência atmosférica mais desconfortável do que no espaço urbano envolvente. Este aspecto assume particular importância em clareiras, especialmente quando ocupadas por lagos de dimensão apreciável. Aqui, o efeito de sombra é atenuado, manifestando-se por um aumento da temperatura, mas a grande disponibilidade em água e uma atmosfera mais dificilmente movimentada por efeito do povoamento arbóreo envolvente, impede uma diminuição sensível da humidade relativa.

Todos estes aspectos topoclimáticos devem ser considerados em acções de intervenção urbana em Coimbra, quer quanto ao tipo de ocupação do solo e à morfologia urbana, como até à propria arquitectura dos espaços verdes, passando pelo tipo de povoamento vegetal.

Atendendo às características do clima regional, as eventuais condições atmosféricas de maior desconforto bioclimático surgem relacionadas com temperaturas diurnas no Verão ou com temperaturas nocturnas no Inverno.

Assim, nos espaços verdes vocacionados para o lazer, é desaconselhável do ponto de vista bioclimático a existência de clareiras muito abertas e ocupadas 
com lagos de grandes dimensões, sendo de privilegiar povoamentos arbóreos que aumentem o efeito de sombra, sem que simultaneamente contribuam para um excessivo aumento da humidade relativa.

No caso dos espaços construídos é também de privilegiar o aumento do efeito de sombra através de uma significativa ocultação do horizonte. Nos locais onde, atendendo à morfologia urbana, a ocultação do horizonte não seja significativa, como é o caso de avenidas largas, praças e espaços abertos em geral, os benefícios bioclimáticos da sua arborização são significativos, tanto pela atenuação das temperaturas diurnas de Verão, como pela atenuação do arrefecimento nocturno no Inverno.

Quanto aos riscos de poluição atmosférica, os efeitos do Jardim Botânico e do Parque de Santa Cruz, se por um lado são benéficos pelo seu papel de "limpeza" do ar, por outro podem traduzir-se numa intensificação local de situações inibidoras da dispersão de poluentes, especialmente no caso do Jardim de Santa Cruz pelo seu contex to topográfico. No entanto, tais riscos de poluição atmosférica não assumem proporções significativas, dada a sua restrição espacial e temporal. Mas podem ser minimizados, noutras áreas da cidade a urbanizar num futuro próximo, em semelhante contex to topográfico. É o caso de espaços verdes planeados para o sector superior de vales. Aqui os talvegues deverão ser objecto de restrições quanto à densidade de construção e à dimensão vertical dos edifícios, por forma a que a urbanização não interfira no escoamento nocturno do ar, assegurando a sua renovação, sem acentuar eventuais situações de inversão térmica, inibidoras da dispersão de poluentes.

Mas, nãose pode, nem deve, a partir do diagnóstico de situações associadas a dois espaços verdes, generalizar para todo o espaço envolvente. Cada área de intervenção urbanística deve ser objecto de um estudo prévio à implementação do plano de urbanização, que possa nortear determinados aspectos da ocupação do espaço, por forma a que esta se harmonize com o meio ambiente em que se insere.

\section{BIBLIOGRAFIA:}

BARRY, R. G.; CHORLEY, R. J. (1985) - Atmósfera, Tiempo y Clima (4a Edição). Omega, Barcelona, 500p.

COCA, M. A. A. (1992) - "Aspectos climáticos del parque del Retiro (Madrid)”. Estudios Geográficos, 53, 207, pp. 217-239.

ESCOURROU, G. (1981) - Climat et Environnement. Les facteurs locaux du climat. Masson, Paris, 182p.
ESCOURROU, G. (1991) - Le Climat et la Ville. Nathan, $191 \mathrm{p}$.

GANHO, N. (1992a) - O Clima Urbano de Coimbra - Aspectos térmicos estivais. Dissertação de Mestrado em Geografia apresentadaà Faculdade de Letras da Universidade de Coimbra, 170 p. +80 p. extra texto de gráficos e figuras.

GANHO, N.'(1992b) - "A ilha de calor de Coimbra - Resultados de observações itinerantes de temperatura no interior do tecido urbano". Actas do VI Colóquio Ibérico de Geografia, Porto (em publicação).

GANHO, N. (1995a) - "La isla de calor de Coimbra bajo diferentes condiciones de tiempo de Verano". Estudios Geográficos, LVI, 219, pp. 285-317.

GANHO, N. (1995b) - "A ilha de calor de Coimbra sob diferentes condiçōes de tempo de Verão". Territorium, 2, pp. 33-50.

GEIGER, R. (196!) - Manual de Microclimatologia. O clima da camada de ar junto ao solo (4a Eơição). Fundação Calouste Gulbenkian, Lisboa, 639p.

GILES, D. B.; BALAFOUTIS, C.; MAHERAS, P. (1990) - "Too hot for confort: The heatwaves in Greece in 1987 and 1988". International Journal of Biometeorology, 34, pp. 98-104.

GIVONI, B. (1991) - "Impact of planted areas on urban environmental quality: a review". Atmospheric Environment, 25-B, 3, pp. 289-299.

HUANG, Y. J.; AKBARI, H.; TAHA, H.; ROSENFELD, A. H. (1987) - "The potential of vegetation in reducing summer cooling loads in residential buildings". Journal of Climate and Applied Meteorology, 26, pp. 1103-1116.

LANDSBERG, H. E. (1981) - The Urban Climate . Academic Press, New York, 275p.

LÓPEZGÓMEZ, A.; LÓPEZ GÓMEZ, J.;FERNÁNDEZGARCÍA, F.; ILERA, F. A. (1991) - El Clima Urbano de Madrid: la isla de calor. C.S.I.C., Madrid, 166p.

LÓPEZ GÓMEZ, A.; FERNÁNDEZ GARCÍA, F.; ARROYO, F.; MARTÍN VIDE, J.; CUADRAT, J. M. (1993) - El Clinia de las Ciudades Españolas. Cátedra, Madrid, 268p.

MATHER, J. R. (1974) - Climatology: Fundamentals and Applications. McGraw-Hill, New York.

OKE, T, R. (1987) - Boundary Layer Climates. Routledge, London, $435 p$.

OLIVER, J.E. (1981) - Climatology: Selected Applications . Eduard Arnold Ltd., London.

PARKER, J. H. (1983) - "The effectiveness of vegetation on residential cooling". Passive Solar Joumal, 2, pp. 123-132.

PARKER, J. H. (1987) - "The use of shrubs in energy conservation plantings". Landscope Journal, 6, pp. 132-139.

PARKER, J. H. (1989) - "The impact of vegetation on air conditioning consumption". Procedings, Conference on Controlling the Summer Heat Island, LBL-27872, pp. 46-52. 


\section{ANEXO}

Quadro 9

Parâmetros de tendência central e de dispersão das temperaturas e humidades relativas, relativas ao IGU, em manhãs de Inverno (amostra: 7 percursos de observação iniciados entre as 9.40 e as 11.41 horas locais dos neses de Novembro e Dezembro de 1994, e Janeiro de 1995)

\begin{tabular}{|c|c|c|c|c|c|c|c|c|c|c|c|c|c|c|c|c|c|c|}
\hline $\mathrm{Tr}^{\circ} \mathrm{C}$ & P1 & P2 & P3 & $\mathrm{P} 4$ & P5 & P6 & P7 & $\mathbf{P 8}$ & PO & Pto & P11 & P12 & $\mathrm{P} 13$ & P14 & P15 & $P 16$ & P17 & $P 18$ \\
\hline média & 0.4 & 0.3 & -0.3 & -0.7 & -1.1 & 0.2 & 0.5 & 0.7 & -0.3 & -1.1 & -0.2 & -0.1 & -0.2 & -0.2 & 0.5 & 0.6 & 0.6 & 1.3 \\
\hline mediana & 0.6 & 0.3 & -0.5 & -0.9 & -1.4 & 0.2 & 0.1 & 0.8 & -0.5 & -1.3 & -0.2 & 0.1 & 0.0 & -0.4 & 0.3 & 0.7 & 0.5 & 1.3 \\
\hline $\begin{array}{l}\text { desvio- } \\
\text { padrāoo }\end{array}$ & 0.7 & 0.5 & 0.7 & 0.8 & 0.9 & 0.8 & 0.9 & 0.7 & 0.7 & 1.2 & 0.8 & 0.8 & 0.8 & 1.2 & 1.1 & 0.7 & 0.9 & 0,8 \\
\hline máx. & 1.4 & 1.4 & 1.3 & 1.4 & 0.9 & 1.6 & 2.1 & 2.2 & 0.7 & 1.1 & 1.4 & 1.8 & 1.0 & 2.5 & 2.7 & 2.0 & 1.8 & 3.1 \\
\hline $\mathrm{min}$. & -0.8 & -0.4 & -1.1 & -1.5 & -2.8 & -1.3 & -1.1 & -0.6 & -1.7 & -2.9 & -1.9 & .1 .1 & -1.8 & -2.5 & -1.7 & -0.3 & -1.2 & 0.0 \\
\hline
\end{tabular}

\begin{tabular}{|c|c|c|c|c|c|c|c|c|c|c|c|c|c|c|c|c|c|c|}
\hline HRr\% & P1 & $P 2$ & $\mathrm{P3}$ & P4 & $P 5$ & P6 & $P 7$ & $P 8$ & $\mathrm{Pg}$ & P10 & P11 & P12 & P13 & P14 & P15 & P16 & P17 & P18 \\
\hline média & 0.9 & 1.1 & 4.0 & 6.2 & 9.1 & 0.4 & 0.9 & 0.4 & 3.7 & 7.1 & 2.9 & 0.7 & 0.9 & 1.6 & 0.2 & -1.4 & -1.5 & -3.3 \\
\hline mediana & 1.5 & 1.0 & 3.0 & 7.0 & 8.5 & 0.0 & 1.5 & 1.0 & 3.5 & 7.0 & 3.0 & 0.5 & 1.0 & 1.0 & 0.5 & -1.0 & -2.0 & -4.0 \\
\hline $\begin{array}{l}\text { desvio- } \\
\text { padrāoo }\end{array}$ & 3.7 & 24 & 4.0 & 5.0 & 4.9 & 4.1 & 3.7 & 2.3 & 3.3 & 7.0 & 2.7 & 2.7 & 3.7 & 5,0 & 5.0 & 4.5 & 4.8 & 4.6 \\
\hline max. & 6 & 6 & 11 & 12 & 18 & 8 & 6 & 4 & 10 & 19 & 10 & 5 & 8 & 11 & 10 & 6 & 8 & 7 \\
\hline $\min$. & -8 & -4 & -2 & -4 & 2 & -6 & -7 & -4 & -2 & -5 & -1 & -6 & -8 & -10 & -10 & -12 & -12 & -12 \\
\hline
\end{tabular}

Quadro 10

Parâmetros de tendência central e de dispersão das temperaturas e humidades relativas, relativas ao IGU, em tardes de Inverno (amostra: 14 percursos de observação iniciados entre as $13.43 \mathrm{e}$ as 17.47 horas locais dos meses de Novembro e Dezembro de 1994, e Janeiro de 1995)

\begin{tabular}{|c|c|c|c|c|c|c|c|c|c|c|c|c|c|c|c|c|c|c|}
\hline $\operatorname{Tr}^{\circ} \mathrm{C}$ & P1 & $\mathrm{P} 2$ & P3 & P4 & P5 & P6 & P7 & PB & P9 & P10 & P11 & $P 12$ & $P 13$ & $P 14$ & P15 & P16 & P17 & P18 \\
\hline média & 1.0 & 0.6 & 0.0 & -0.4 & -0.6 & 0.2 & 0.4 & 0.9 & 0.5 & -0.6 & 0.0 & 0.4 & 0.3 & 0.2 & 0.7 & 0.4 & 0.9 & 0.7 \\
\hline mediana & 0.8 & 0.5 & -0.6 & -0.5 & -0.7 & 0.3 & 0.4 & 0.6 & 0.2 & -1.0 & -0.3 & 0.3 & 0.3 & 0.0 & 0.5 & 0.0 & 0.8 & 0.7 \\
\hline $\begin{array}{l}\text { desvio- } \\
\text { padrão }\end{array}$ & 0.9 & 0.7 & 0.6 & 0.9 & 1.0 & 0.4 & 0.4 & 0.6 & 1.0 & 1.0 & 0.6 & 0.9 & 0.9 & 1.0 & 1.0 & 1.2 & 0.9 & 0.8 \\
\hline máx. & 2.8 & 1.4 & 0.9 & 1.3 & 0.9 & 0.7 & 1.2 & 1.9 & 2.2 & 1.5 & 1.3 & 1.7 & 1.5 & 2.1 & 2.6 & 3.0 & 2.8 & 2.4 \\
\hline $\min$. & 0.1 & -0.4 & -0.7 & -1.3 & -2.1 & -0.6 & -0.2 & 0.4 & -0.5 & -1.6 & -0.5 & -0.5 & -0.8 & -0.9 & -0.2 & -0.5 & 0.0 & 0.0 \\
\hline
\end{tabular}

\begin{tabular}{|c|c|c|c|c|c|c|c|c|c|c|c|c|c|c|c|c|c|c|}
\hline HAr\% & P1 & P2 & P3 & P4 & P5 & P6 & P7 & P8 & P9 & P10 & P11 & P12 & P13 & P14 & P15 & P16 & P17 & P18 \\
\hline médiá & 0.4 & 1.6 & 3.7 & 7.4 & 10.0 & 2.4 & 1.4 & 0.1 & 2.7 & 6.4 & 3.4 & 1.9 & 2.0 & 2.4 & 0.6 & 0.9 & 0.0 & -0.7 \\
mediana & -1.0 & 1.0 & 4.0 & 8.0 & 10.0 & 2.0 & 1.0 & 2.0 & 3.0 & 6.0 & 3.0 & 2.0 & 3.0 & 4.0 & 1.0 & 2.0 & 1.0 & 0.0 \\
desvio- & 4.6 & 3.5 & 3.8 & 5.0 & 7.3 & 3.7 & 3.0 & 2.7 & 2.8 & 5.5 & 3.3 & 2.4 & 2.8 & 4.4 & 4.8 & 5.5 & 5.2 & 4.8 \\
padrăó & 9 & 6 & 10 & 13 & 21 & 9 & 6 & 3 & 6 & 12 & 8 & 4 & 5 & 7 & 7 & 7 & 6 & 5 \\
máx. & 9 & 6 & -1 & -1 & -1 & -2 & -3 & -3 & -2 & -1 & -2 & -3 & -4 & -6 & -8 & -9 & -8 & -7 \\
min. & -4 & -3 & -1 &
\end{tabular}

Quadro 11

Parâmetros de tendência central e de dispersão das temperaturas e humidades relativas, relativas ao IGU, em tardes de Verão (amostra: 5 percursos de observaçāo iniciados entre as 15.00 e as 15.25 horas locais dos meses de Junho e Julho de 1995)

\begin{tabular}{|c|c|c|c|c|c|c|c|c|c|c|c|c|c|c|c|c|c|c|}
\hline Tr'C & P1 & P2 & P3 & P4 & P5 & P6 & P7 & P8 & P9 & P10 & P11 & P12 & P13 & P14 & P15 & P16 & P17 & P18 \\
\hline média & 1.8 & 1.1 & 0.5 & 0.8 & 0.6 & 1.1 & 1.6 & 1.6 & 0.5 & 0.6 & 1.1 & 1.5 & 0.9 & 1.4 & 0.9 & 1.0 & 0.6 & 0.1 \\
mediana & 1.8 & 1.3 & 0.8 & 1.2 & 0.6 & 1.0 & 1.4 & 1.3 & 0.5 & 0.5 & 1.1 & 1.3 & 1.0 & 1.0 & 1.4 & 1.5 & 1.3 & 0.3 \\
desvio- & 0.7 & 1.2 & 1.0 & 1.4 & 1.3 & 1.3 & 1.2 & 1.1 & 0.2 & 0.8 & 0.8 & 1.7 & 1.5 & 1.6 & 1.3 & 1.2 & 1.4 & 1.2 \\
padrắo & & & 1.2 & 1.9 & 1.9 & 2.3 & 3.3 & 3.5 & 0.7 & 2.0 & 2.4 & 3.5 & 2.3 & 3.4 & 2.0 & 1.8 & 1.6 & 1.1 \\
máx. & 2.5 & 2.0 & 1.6 & 1.9 & -1.1 & -0.8 & 0.1 & 0.7 & 0.2 & -0.1 & 0.1 & -0.3 & -1.4 & -0.8 & -1.3 & -1.1 & -1.9 & -1.8 \\
\hline
\end{tabular}

\begin{tabular}{|c|c|c|c|c|c|c|c|c|c|c|c|c|c|c|c|c|c|c|}
\hline HRr\% & P1 & $\mathrm{P2}$ & P3 & P4 & P5 & PE & P7 & $\mathrm{PB}$ & PQ & P10 & P11 & P12 & $P 13$ & P14 & P15 & P16 & $P 17$ & $P 18$ \\
\hline média & -27.6 & -26.0 & -22.6 & -21.0 & -23.0 & -25.8 & -28.0 & -31.4 & -26.0 & -24.0 & -28.4 & -32.0 & -30.6 & -31.8 & -29.8 & -29.9 & -29.4 & -29.0 \\
\hline mediana & -27.0 & -27.0 & -23.0 & -19.0 & -22.0 & -27.0 & -27.0 & -32.0 & -25.0 & -26.0 & -30.0 & -32.0 & -31.0 & -35.0 & -31.0 & -29.0 & -28 & -29.0 \\
\hline $\begin{array}{l}\text { desvio- } \\
\text { padrāo }\end{array}$ & 1.8 & 3.7 & -2.7 & 3.2 & 3.9 & 1.6 & 3.4 & 3.5 & 3.8 & 3.9 & 3.3 & 3.8 & 4.9 & 5.4 & 2.2 & 3.1 & 3.1 & 3.5 \\
\hline máx. & -26 & -20 & -19 & -18 & -19 & -24 & -24 & -27 & -22 & -20 & -24 & -27 & -24 & .25 & -27 & -26 & -26 & -25 \\
\hline $\min$. & -30 & -30 & -26 & -25 & -28 & -27 & -32 & -36 & -32 & -28 & .32 & .37 & -37 & -36 & -32 & -33 & -34 & .33 \\
\hline
\end{tabular}

